\title{
Microcosm experiments to control anaerobic redox conditions when studying the fate of organic micropollutants in aquifer material
}

\author{
Manuela Barbieri a,b,*, Jesús Carrera ${ }^{a}$, Xavier Sanchez-Vila ${ }^{\text {b }}$, Carlos Ayora a , Jordi Cama ${ }^{\text {a }}$ \\ Marianne Köck-Schulmeyer ${ }^{\mathrm{c}}$, Miren López de Alda ${ }^{\mathrm{c}}$, Damià Barceló ${ }^{\mathrm{c}}$, \\ Joana Tobella Brunet ${ }^{\mathrm{d}}$, Marta Hernández García ${ }^{\mathrm{d}}$ \\ a GHS, Institute of Environmental Assessment and Water Research (IDAEA), CSIC, Jordi Girona 18-26, 08034 Barcelona, Spain \\ b GHS, Department of Geotechnical Engineering and Geosciences, Universitat Politecnica de Catalunya, UPC-BarcelonaTech, Jordi Girona 1-3, Modul D-2, 08034 Barcelona, Spain \\ ' Department of Environmental Chemistry, Institute of Environmental Assessment and Water Research (IDAEA), CSIC, Jordi Girona 18-26, 08034 Barcelona, Spain \\ d CETaqua, Water Technology Centre, Carretera de Esplugues 75, 08940 Cornellà de Llobregat, Barcelona, Spain
}

\section{A R T I C L E I N F O}

Article history:

Received 30 November 2010

Received in revised form 20 August 2011

Accepted 9 September 2011

Available online 21 September 2011

\section{Keywords:}

Artificial recharge

Denitrification

Manganese reducing

Iron reducing

Sulfate reducing

Atenolol

\begin{abstract}
A B S T R A C T
The natural processes occurring in subsurface environments have proven to effectively remove a number of organic pollutants from water. The predominant redox conditions revealed to be one of the controlling factors. However, in the case of organic micropollutants the knowledge on this potential redox-dependent behavior is still limited. Motivated by managed aquifer recharge practices microcosm experiments involving aquifer material, settings potentially feasible in field applications, and organic micropollutants at environmental concentrations were carried out. Different anaerobic redox conditions were promoted and sustained in each set of microcosms by adding adequate quantities of electron donors and acceptors. Whereas denitrification and sulfate-reducing conditions are easily achieved and maintained, Fe- and Mn-reduction are strongly constrained by the slower dissolution of the solid phases commonly present in aquifers. The thorough description and numerical modeling of the evolution of the experiments, including major and trace solutes and dissolution/ precipitation of solid phases, have been proven necessary to the understanding of the processes and closing the mass balance. As an example of micropollutant results, the ubiquitous beta-blocker atenolol is completely removed in the experiments, the removal occurring faster under more advanced redox conditions. This suggests that aquifers constitute a potentially efficient alternative water treatment for atenolol, especially if adequate redox conditions are promoted during recharge and long enough residence times are ensured.
\end{abstract}

(c) 2011 Elsevier B.V. All rights reserved.

\section{Introduction}

The ultimate motivation of this work is artificial recharge of aquifers. Artificial recharge is beneficial both in quantitative (augmentation of groundwater resources, long term underground storage, etc.) and qualitative terms (overall improvement of water quality during aquifer passage: decreasing of

\footnotetext{
* Corresponding author at: GHS, Institute of Environmental Assessment and Water Research (IDAEA), CSIC, Jordi Girona 18-26, 08034 Barcelona, Spain. Tel.: +34 934006100x626(office).

E-mail address: manuela.barbieri1@gmail.com (M. Barbieri).
}

suspended solids, pathogens, nitrogen, phosphates, metals and dissolved organic carbon). The interest in this technique is also related to the capability of subsoil processes to partially or totally remove organic contaminants from water (Aronson et al., 1999 and references therein; Christensen et al., 2001 and references therein; Neuhauser et al., 2009). Nowadays a great scientific effort is dedicated to assess whether organic micropollutants could also be effectively removed (Barber et al., 2009; Díaz-Cruz and Barceló, 2008 and references therein; Heberer, 2007 and references therein; Hoppe-Jones et al., 2010). A number of such compounds are not eliminated by conventional water treatments (Gros et al., 2010; Onesios 
et al., 2009 and references therein; Petrovic et al., 2009 and references therein; Stackelberg et al., 2007). The passage of water through the soil-aquifer system during artificial recharge may represent an alternative or complementary treatment for their removal.

As a general rule, the fate of organic pollutants within the aquifer depends on lithology, hydraulic and textural properties of the soil, temperature, physico-chemical properties of the specific compound, and microbial environment. Among all factors, the predominant redox state of the aquifer revealed to play a significant role (Aronson et al., 1999 and references therein; Bosma et al., 1996; Broholm and Arvin, 2000 and references therein; Christensen et al., 2001; Kao et al., 2003 and references therein). Since certain pollutants could be preferably removed under some particular redox conditions, such conditions could eventually be promoted in artificial recharge practices. Even more important, if different compounds are degraded under different redox environments, a water mass undergoing a sequence of redox states should have most of its initial contaminants eliminated.

Yet, in the case of organic micropollutants, the knowledge on a potential redox-dependent behavior is still limited. Beside field evidences (Drewes et al., 2003; Heberer et al., 2008; Montgomery-Brown et al., 2003; Pavelic et al., 2005; Tubau et al., 2010; and references therein), laboratory tests under specific and controlled simplified conditions have been
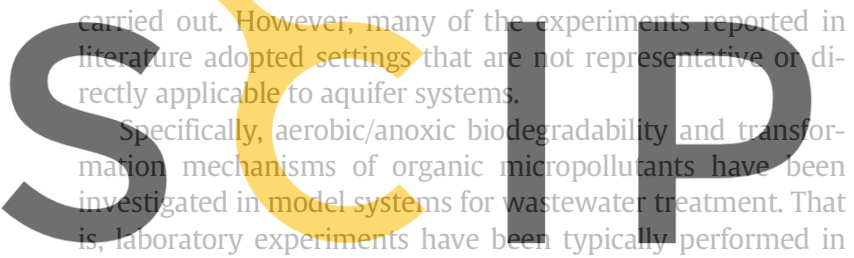

wastewater matrices, and by using sludges from sewage treat-

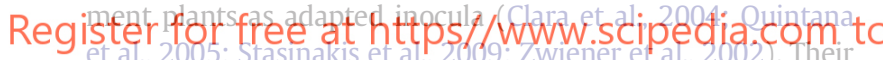

fate under aerobic/anaerobic or specific redox conditions have also been largely studied in aquatic environments. In these cases river-bed sediments rich in organic materials have been incubated with river water (Davis et al., 2006; Löffler et al., 2005; Radke et al., 2009) or with solutions/culture media containing specific electron acceptors (Bradley et al., 2001; Crawford et al., 1998; Lu et al., 2009; Somsamak et al., 2001). Some tests involved bacterial isolates, and have been carried out using standard silica sand or sintered materials as solid matrix for the colonization of the microorganisms (Crawford et al., 2000; Katz et al., 2001; Stucki et al., 1995). Finally, not only in the aforementioned studies but also when soil and aquifer material were included (Krueger et al., 1998; Schulz et al., 2008; Ying et al., 2008), the experiments have been often performed with concentrations of the target compounds from hundreds of $\mu \mathrm{g} \mathrm{L}^{-1}$ to tens of $\mathrm{mg} \mathrm{L}^{-1}$.

The above works are indeed useful to demonstrate the susceptibility of specific micropollutants to microbial or abiotic transformation, to understand degradation pathways, and to identify intermediate or stable metabolites. However, the organic content of aquifer materials, which may influence sorption and partitioning behavior of organic micropollutants, could be lower, the potential development of a sequence of redox states and the removal of micropollutants depends on the local native microorganisms, and target pollutants are found at concentrations some order of magnitudes lower.

Finally, quite limited laboratory experiments, a number of them related to managed aquifer recharge practices, resemble real subsurface environments (Baumgarten et al., 2011; Hua et al., 2003; Mansell and Drewes, 2004; Massmann et al., 2008; Rauch-Williams et al., 2010; Scheytt et al., 2004). In such experiments, the fate of organic micropollutants has been usually assessed within the range of redox conditions developing naturally in the system and being representative of those actually occurring at field site, namely aerobic, anoxic (prevailing denitrifying) and seldom unspecified anaerobic conditions. The identification of potential abiotic processes by performing analogous sterile experiments was not always included in such studies. Therefore, the potential effect of various redox states (especially the most reducing ones) on the fate of a wide range of organic micropollutants in subsurface environments still remains to be investigated.

In this context, the aim of our work was to create and sustain diverse anaerobic redox conditions in systems involving natural aquifer material and settings potentially feasible in artificial recharge sites, and to study in such environments the behavior of organic micropollutants at realistic concentrations.

The present paper describes thoroughly the experimental methodology and settings adopted. Details on the selection of the type/quantities of electron donors and acceptors used to
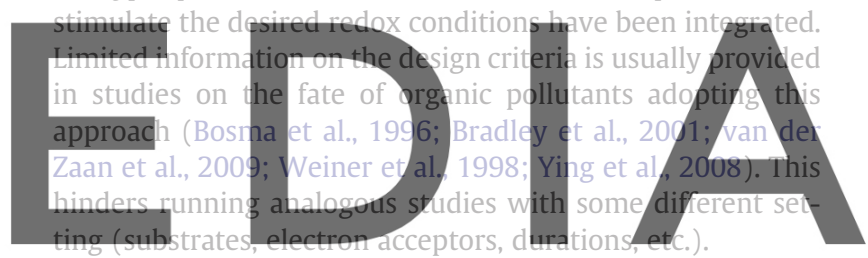

The description of the microcosms' hydrochemical evolu-

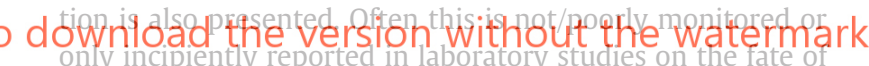

organic contaminants, especially when focused on their transformation pathways, nor the actual occurrence of the expected/stimulated redox condition is verified (Baumgarten et al., 2011; Bosma et al., 1996; Bradley et al., 2001; Gröning et al., 2007; Krueger et al., 1998; Rauch-Williams et al., 2010; Schulz et al., 2008; van der Zaan et al., 2009; Weiner et al., 1998; Ying et al., 2008). We conjecture that the assessment of the geochemical state, which could be quite complex as in natural subsurface environments, and its quantitative numerical modeling has to be included in this type of studies for a more complete interpretation of the experimental results, and for the potential subsequent design of real field applications.

Finally, as example of application of the study to the fate of organic micropollutants in different redox environments, the results for the ubiquitous but still barely investigated $\beta$-blocker atenolol are presented in the paper.

\section{Materials and methods}

\subsection{Sediments, water and micropollutants}

The experimental set up included various sets of microcosms, each microcosm consisting of natural sediments and synthetic water spiked with a mixture of organic micropollutants. 
Sediments were obtained from a test site for artificial recharge of groundwater located in Sant Vicenç dels Horts (Barcelona, Spain). The aquifer consists of quaternary alluvial sediments, mainly gravel and sand with a small fraction of lutites. Sediment samples for the experiments were collected prior to the starting up of the facilities, from a pit excavated in the bottom of the infiltration pond, namely from an oxic unsaturated horizon at about $1 \mathrm{~m}$ depth. They were sieved through a $1 \mathrm{~mm}$ grid to remove the coarse fraction, which was expected to be less active for surface and microbially mediated reactions. The sieved sediments were immediately used for assembling the microcosms or stored for a maximum of 2 days at $25^{\circ} \mathrm{C}$ inside aluminum paper.

Chemical and mineralogical characteristics of the sediments used in the experiments are summarized in Table S1 of the Supporting Information. X-ray diffraction (XRD) of powdered samples was used in an attempt to identify the minerals present in the sediment. Analysis was performed with a Bruker D-5005 diffractometer. Results were obtained using Cu radiation, with secondary Graphite monochromator. The analytical conditions were: $\theta / 2 \theta$ geometry, collecting data in the range $(2 \theta)$ between $4^{\circ}$ and $60^{\circ}$ with a step scan of $0.05^{\circ}, 3 \mathrm{~s}$ per step measuring time. The evaluation of the spectra was made by using the Diffrac.Suite ${ }^{\mathrm{TM}}$ software and identification of chemical compounds by means of the PDF database Release 2001, Data Sets 1-51 plus 70-89.

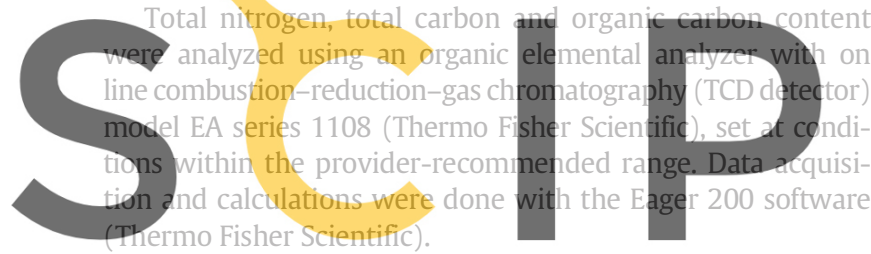

The grain size distribution was measured with the Laser

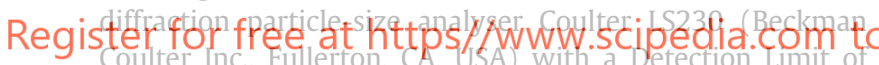

0.04 um. The content in Mn and Fe(III) associated to oxidehydroxides and oxides was obtained by sequential extraction (steps 1 to 4 from Dold, 2003).

Water used for the preparation of all the experiments, called "common water" in the following, was artificially prepared to mimic the recharge water at the test site (from the Llobregat river water) except for the organic carbon content, which at this stage was set equal to zero. Its theoretical composition is shown in Table S2 of the Supporting Information.

The mixture of organic micropollutants used in all experiments included drugs (atenolol, carbamazepine, diclofenac, gemfibrozil, ibuprofen, sulfamethoxazole), pesticides (atrazine, simazine, terbuthylazine, prometryn, diuron, chlorphenvinfos, chlorpyrifos, diazinon), estrogens (estrone, $\beta$-estradiol), PAHs (naphthalene, acenaphthene, fluorene, anthracene, Phenanthrene, benz[a]anthracene, chrysene, pyrene, fluoranthene, benzo[b]fluoranthene, benzo[k]fluoranthene, benzo[a]pyrene, dibenzo[a]anthracene, indeno[1,2,3-cd]pyrene and benzo[ghi] perylene), surfactant degradation products (4-tert-octylphenol, 4-nonylphenol), a phthalate (bis-diethylhexyl phthalate) and a biocide (triclosan). The selection of the compounds was based on the micropollutants occurrence in the Llobregat river (Céspedes et al., 2005; Muñoz et al., 2009; RodriguezMozaz et al., 2004).
High purity (>96\%) analytical standards of atenolol, carbamazepine, diclofenac, gemfibrozil, ibuprofen, simazine, diuron and estrone, and of the isotopic analog atenolol $d 7$ used as surrogate standard for quantification of atenolol were supplied by Sigma-Aldrich. The standard containing the 16 PAHs at a concentration of $2000 \mathrm{mg} \mathrm{L}^{-1}$ in dichloromethane:benzene (1:1) as well as high purity (>96\%) analytical standards of all the remaining compounds were purchased from AccuStandar. Individual stock solutions were prepared in methanol or in an appropriate solvent according to their properties. Working standard mixtures were then prepared at different concentrations by dilution of the individual stock solutions in methanol, and were used to prepare the spiking solution for the experiments (resulting concentration in the "initial water" described in Section 2.4 was $10 \mu \mathrm{L} \mathrm{L}^{-1}$ for 4-octylphenol and 4-nonylphenol, and $1 \mu \mathrm{g} \mathrm{L}^{-1}$ for the rest of compounds) and to prepare the aqueous calibration standards (concentration range 1-1500 ng L ${ }^{-1}$, surrogate standard $200 \mathrm{ng} \mathrm{L}^{-1}$ ). Stock and working standard solutions were stored at $-20^{\circ} \mathrm{C}$ in the dark.

\subsection{Biotic experiments - creating sustainable redox conditions}

A different anaerobic redox state was promoted in four different sets of batches by stimulating one specific step of

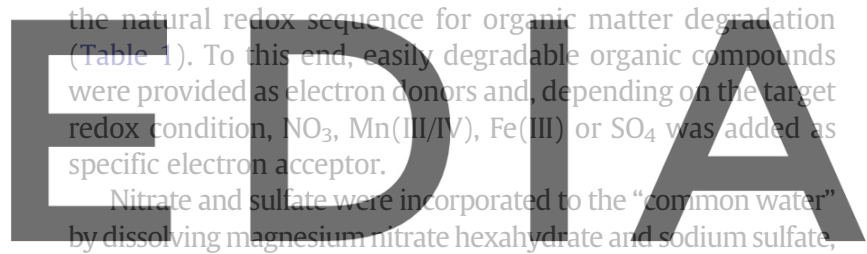

respectively. Mn(III/IV) and Fe(III) oxide-hydroxides were incor-

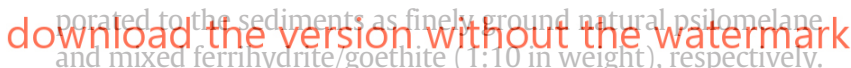

Sodium acetate and the methanol used as solvent in the micropollutants spiking solution were adopted as easily degradable substrates. They were incorporated to the "initial water" (Section 2.4) by dissolving anhydrous sodium acetate and when spiking the micropollutants mixture, respectively. In fact, the organic micropollutants introduced represented potential electron donors too, but their concentrations were so low that their effect on redox condition build-up was expected to be minimal.

The selection of the type of substrate was based on a revision of the existing literature and on preliminary scoping experiments (results not shown) regarding the degradation feasibility and rate for different organic compounds. Ideally, the selected substrate should promote the build-up of the desired redox conditions after a short lag-phase and form a small number of intermediate compounds (possibly being not fermentable) to facilitate the assessment of the chemical evolution of the system.

The total amounts of organic substrate and controlling electron acceptor were selected so as to reach the desired redox state and to sustain it during a significant lapse of time. This implies on one hand that the total amount of organic substrate had to be large enough to consume electron acceptors with reactions energetically more favorable than the target one. 
Table 1

Sequence of the overall redox reactions for the microorganisms mediated degradation of organic matter (i.e. methanol and acetate ions in the present experiments). Biomass growth is ignored in the stoichiometries.

\begin{tabular}{|c|c|c|c|}
\hline $\begin{array}{l}\text { 1a) } \mathrm{CH}_{3} \mathrm{OH}+1.5 \mathrm{O}_{2} \rightarrow \mathrm{HCO}_{3^{-}}+\mathrm{H}^{+}+\mathrm{H}_{2} \mathrm{O} \\
\text { 1b) } \mathrm{CH}_{3} \mathrm{COO}^{-}+2 \mathrm{O}_{2}+\rightarrow 2 \mathrm{HCO}_{3^{-}}+\mathrm{H}^{+}\end{array}$ & Aerobic respiration & $\begin{array}{l}\text { Redox } \\
\text { potential }\end{array}$ & $\begin{array}{l}\text { Energy } \\
\text { yield }\end{array}$ \\
\hline $\begin{array}{l}\text { 2a) } \mathrm{CH}_{3} \mathrm{OH}+1.2 \mathrm{NO}_{3^{-}}+0.2 \mathrm{H}^{+} \rightarrow \mathrm{HCO}_{3}^{-}+0.6 \mathrm{~N}_{2}+1.6 \mathrm{H}_{2} \mathrm{O} \\
\text { 2b) } \mathrm{CH}_{3} \mathrm{COO}^{-}+1.6 \mathrm{NO}^{-}+0.6 \mathrm{H}^{+} \rightarrow 2 \mathrm{HCO}_{3}^{-}+0.8 \mathrm{~N}_{2}+0.8 \mathrm{H}_{2} \mathrm{O}\end{array}$ & Nitrate reduction & + & \\
\hline $\begin{array}{l}\text { 3.1a) } \mathrm{CH}_{3} \mathrm{OH}+3 \mathrm{MnO}_{2}(\mathrm{~s})+5 \mathrm{H}^{+} \rightarrow \mathrm{HCO}_{3}^{-}+3 \mathrm{Mn}^{2+}+4 \mathrm{H}_{2} \mathrm{O} \\
\text { 3.1b) } \mathrm{CH}_{3} \mathrm{COO}^{-}+4 \mathrm{MnO}_{2}(\mathrm{~s})+7 \mathrm{H}^{+} \rightarrow 2 \mathrm{HCO}_{3}{ }^{-}+4 \mathrm{Mn}^{2+}+4 \mathrm{H}_{2} \mathrm{O} \\
\text { 3.2a) } \mathrm{CH}_{3} \mathrm{OH}+6 \mathrm{MnOOH}(\mathrm{s})+11 \mathrm{H}^{+} \rightarrow \mathrm{HCO}_{3}{ }^{-}+6 \mathrm{Mn}^{2+}+10 \mathrm{H}_{2} \mathrm{O} \\
\text { 3.2b) } \mathrm{CH}_{3} \mathrm{COO}^{-}+8 \mathrm{MnOOH}(\mathrm{s})+15 \mathrm{H}^{+} \rightarrow 2 \mathrm{HCO}_{3}{ }^{-}+8 \mathrm{Mn}^{2+}+12 \mathrm{H}_{2} \mathrm{O}\end{array}$ & Mn oxide reduction & & increasing \\
\hline $\begin{array}{l}\text { 4a) } \mathrm{CH}_{3} \mathrm{OH}+6 \mathrm{Fe}(\mathrm{OH})_{3}(\mathrm{~s})+11 \mathrm{H}^{+} \rightarrow \mathrm{HCO}_{3}{ }^{-}+6 \mathrm{Fe}^{2+}+16 \mathrm{H}_{2} \mathrm{O} \\
\text { 4b) } \mathrm{CH}_{3} \mathrm{COO}^{-}+8 \mathrm{Fe}(\mathrm{OH})_{3}(\mathrm{~s})+15 \mathrm{H}^{+} \rightarrow 2 \mathrm{HCO}_{3}{ }^{-}+8 \mathrm{Fe}^{2+}+20 \mathrm{H}_{2} \mathrm{O}\end{array}$ & Fe ox/hydroxide reduction & & \\
\hline $\begin{array}{l}\text { 5a) } \mathrm{CH}_{3} \mathrm{OH}+0.75 \mathrm{SO}_{4}^{2-} \rightarrow \mathrm{HCO}_{3}^{-}+0.75 \mathrm{HS}^{-}+0.25 \mathrm{H}^{+}+\mathrm{H}_{2} \mathrm{O} \\
\text { 5b) } \mathrm{CH}_{3} \mathrm{COO}^{-}+\mathrm{SO}_{4}{ }^{2-} \rightarrow 2 \mathrm{HCO}_{3}^{-}+\mathrm{HS}^{-}\end{array}$ & Sulphate reduction & - & \\
\hline
\end{tabular}
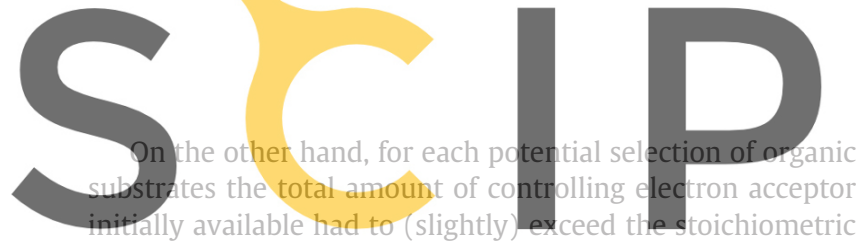

quantity necessary for their complete mineralization. We

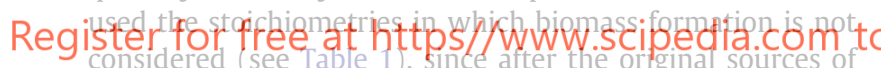

organic carbon have been depleted, dead cells could be recyched and degraded coupling with the reduction of some electron acceptor.

Further details on the selection of the initial amounts of electron donors and acceptors can be found in the Supporting Information (Text S1).

The definitive concentrations of the organic substrates (and the corresponding amount of target electron acceptor) to be initially available in each experiment could be established according to the degradation rates observed in the preliminary rough tests performed when selecting the type of substrates, where their potential toxicity toward microorganisms could be excluded too, and according to the desired duration of the experiments.

Namely, in the present tests the design initial concentration of methanol was fixed by the quantity of spiking solution of micropollutants added to the "initial water", i.e. $2.7 \mathrm{mmol} \mathrm{L}^{-1}$. Regarding acetate, according to the design constraints the selected initial concentrations exceeded natural levels in aquifer system. Still, they were inside the range of concentrations already used in injection experiments and bioremediation scenario in subsurface environments (Baker et al., 1999; Kerkhof et al., 2011), i.e. within a range applicable to a potential stimulation of some specific redox condition in artificial aquifer recharge field sites.

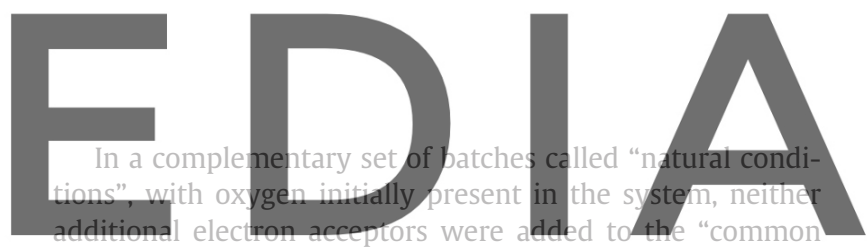

water" or to the sediments, nor was sodium acetate added

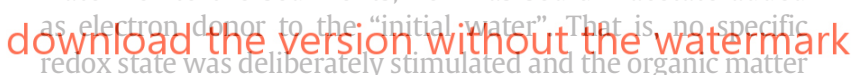

degradation reactions were expected to develop sequentially (Table 1, set "a" of reactions), until complete depletion of either the electron donors or acceptors available in the system. Also in this experiment the design initial concentration of methanol was $2.7 \mathrm{mmol} \mathrm{L}^{-1}$, fixed by the quantity of spiking solutions of micropollutants added to the "initial water" during the assembling procedure.

The initial concentrations of electron donors and electron acceptors present in the five biotic experiments are shown in Table 2. Notice that in the $\mathrm{NO}_{3}$-reducing experiment, due to some unidentified problem during the assembling procedure, some additional $2.9 \mathrm{mmol} \mathrm{L}^{-1}$ of methanol turned out to be present apart from the $2.7 \mathrm{mmol} \mathrm{L}^{-1}$ proceeding from the spiking solution, resulting in an actual initial methanol concentration higher than expected.

\subsection{Abiotic experiment}

A sterile experiment was also conducted as common control reference for the biotic tests to identify potential abiotic processes affecting the micropollutants. The absence of biodegradation processes precludes the evolution of the redox sequence from evolving. Therefore, no information would be gained by repeating the abiotic experiment for each specific electron acceptor. They would never be used. 


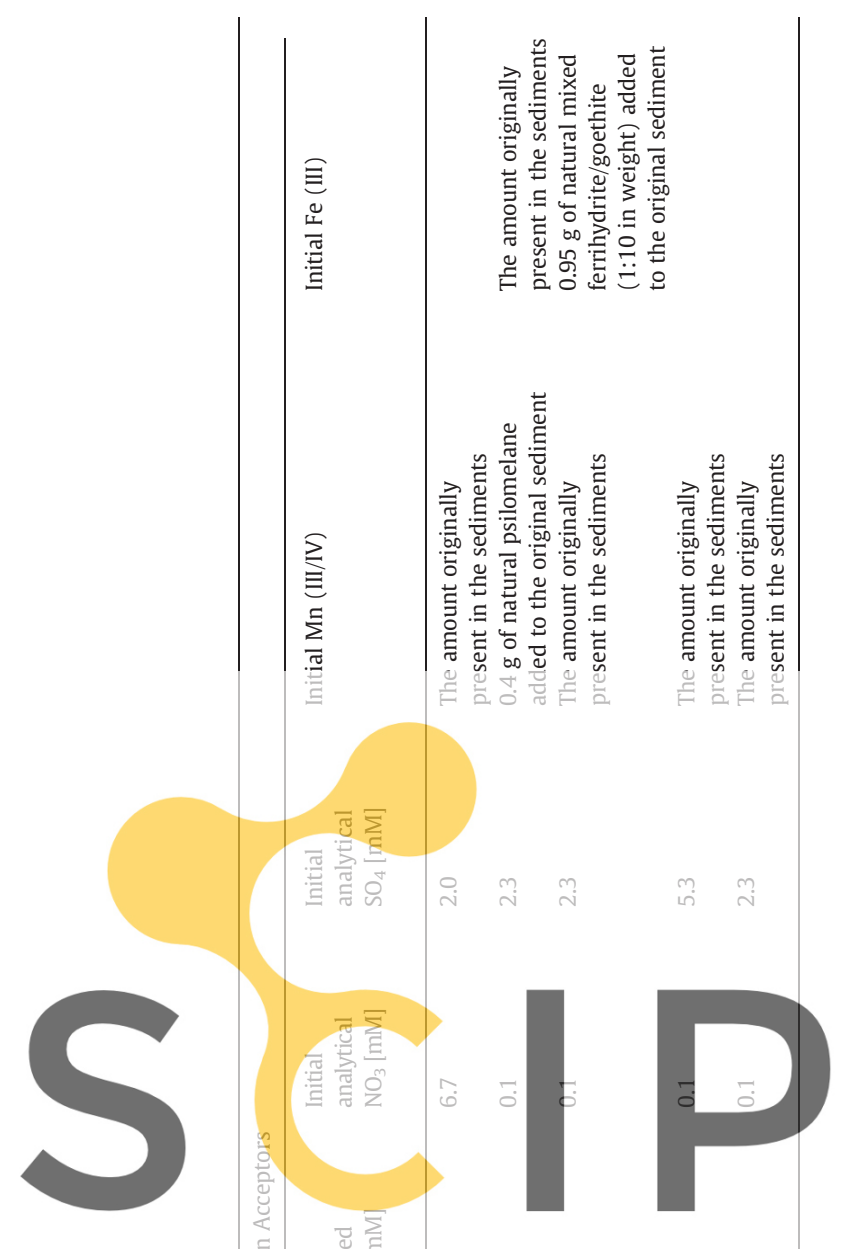

The synthetic water used to prepare this experiment ("abiotic water") consisted in the previously described "common water" plus the same additional amounts of magnesium nitrate hexahydrate and sodium sulfate used respectively in the $\mathrm{NO}_{3}$-reducing and $\mathrm{SO}_{4}$-reducing experiments. Further on, during the assembling procedure (Section 2.4), the same amount of acetate used in the $\mathrm{SO}_{4}$-reducing experiment was added to the sterile "initial water". The initial concentration of methanol was $2.7 \mathrm{mmol} \mathrm{L}^{-1}$, fixed by the quantity of spiking solution of micropollutants added. Thus, in the end, the abiotic experiment was characterized by the maximum $\mathrm{NO}_{3}$, $\mathrm{SO}_{4}, \mathrm{Na}, \mathrm{Mg}$ and DOC concentration existing among the 5 biotic experiments.

Details on the sterilization procedure are given in Section 2.4.1.

\subsection{Experimental procedure}

\subsubsection{Assembling the microcosms}

The collected sediments were air dried at laboratory temperature $\left(25^{\circ} \mathrm{C}\right)$, homogenized in steel containers, and distributed in fractions of $120 \mathrm{~g}$ (air-dry weight) into $0.3 \mathrm{~L}$ glass bottles. The previously defined amounts of Mn(III/IV) or Fe(III) oxidehydroxides powder were mixed with the sediments of each bottle for the Mn(III/IV)- and Fe(III)-reducing experiments, respectively. The $0.3 \mathrm{~L}$ glass bottles were then placed inside a

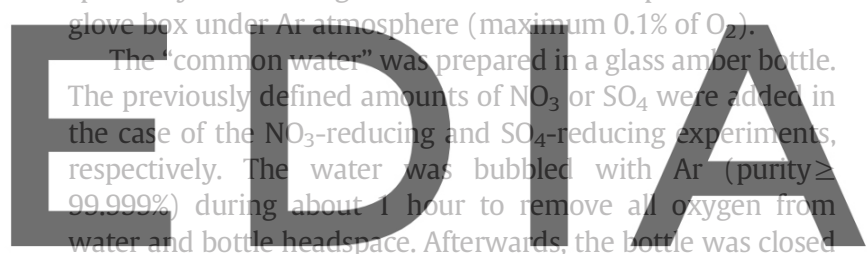

with a screw-cap plus a PTFE protection seal and placed into

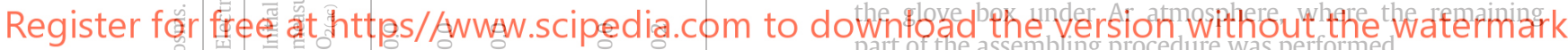

The water was finalized by adding the predefined amount

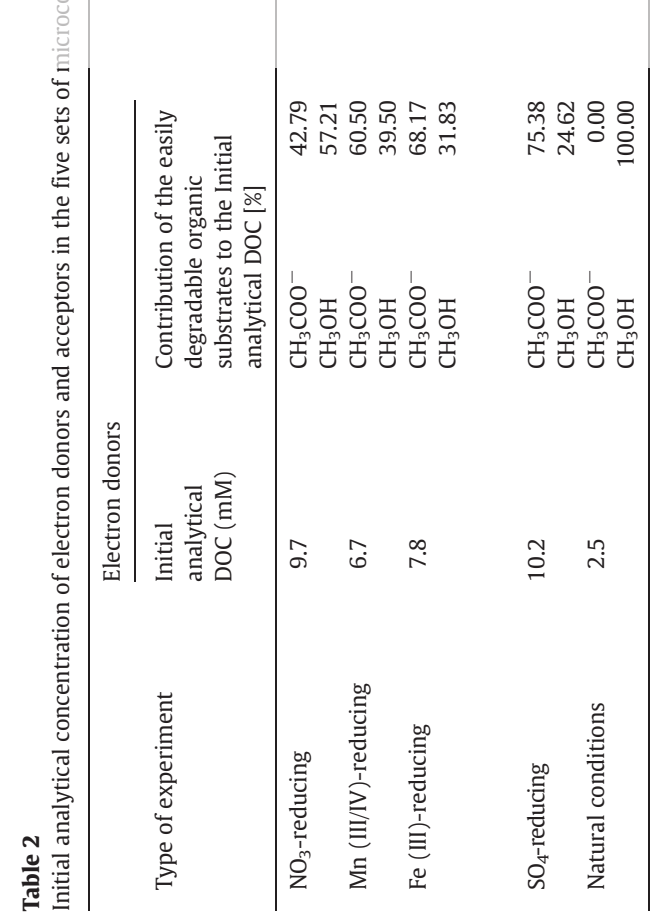

of sodium acetate and the spiking solution of micropollutants. After sampling the resulting "initial water" for chemical analyses, $0.24 \mathrm{~L}$ of it were added to each one of the $0.3 \mathrm{~L}$ glass bottles already containing the sediments. The assembling procedure was concluded by closing the bottles with screwcaps plus a PTFE protection seal, and gently shaking. A remaining headspace of about $15 \mathrm{~mL}$ was left in each bottle.

The bottles were removed from the glove box and enveloped with aluminum foil to prevent photodegradation. Then, they were incubated under controlled temperature $\left(25 \pm 2{ }^{\circ} \mathrm{C}\right)$ and gently shaken few times during their lifetime (once every 2 days during the first week; once a week during the rest of the first month; then, once every 30 to 45 days) as well as the day before being sacrificed.

The "natural conditions" experiment was conducted without Ar bubbling or assembling within a glove box. Instead, dissolved oxygen was allowed in the water and oxygen gas was initially present in the headspace of the bottles.

In the case of the abiotic experiment, prior to the beginning of the assembling procedure, the sediments and the "abiotic water" were sterilized three times (once a day in three consecutive days) with autoclave at $\mathrm{T}=121{ }^{\circ} \mathrm{C}$ and $\mathrm{P}=\mathrm{Patm}+1 \mathrm{~atm}$ for $20 \mathrm{~min}$; moreover, the glove box was sterilized with UV light before entering the material. As an additional precaution, 
$0.22 \mathrm{mmol} \mathrm{L}^{-1}$ of mercury chloride were added (as microbial poison) to the "initial water".

\subsubsection{Disassembling the microcosms}

Duplicate bottles were sacrificed at each sampling time according to predefined sampling schedules (Table S3 of the Supporting Information). These had been defined according to the expected degradation rates of the organic substrates and micropollutants reported in the literature and those estimated in the preliminary scoping experiments (Section 2.2). Some sampling times were set equal for the different experiments, to facilitate comparisons.

One at a time, the two bottles were opened under Ar atmosphere, chemical parameters were measured, and aqueous samples for general chemistry and micropollutants analysis were collected and stored according with each laboratory recommendations.

The sterility of the abiotic experiment was verified six times along its duration. An aliquot of water from devoted microcosms was spread on tryptic soy agar (TSA) plates and incubated in duplicate at $25^{\circ} \mathrm{C}$ under aerobic conditions (for 1 week) and anaerobic conditions (for 2 weeks). None of the plates demonstrated microorganism growth.

2.5. Monitoring and analysis

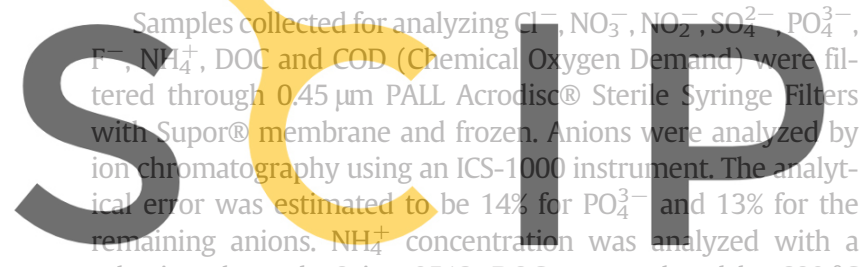
selective electrode Orion 9512. DOC was analyzed by $680^{\circ} \mathrm{C}$

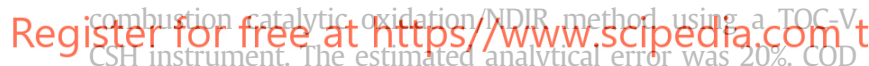
was analyzed by colorimetry with the spectrophotometer Spectioquant Nova 60.

Samples for the analysis of Fe and $\mathrm{Mn}, \mathrm{Ca}, \mathrm{Mg}, \mathrm{Na}, \mathrm{K}$ and minor elements were also filtered at $0.45 \mu \mathrm{m}$, acidified and stored at $4{ }^{\circ} \mathrm{C}$. They were later analyzed by inductively coupled plasma atomic emission spectrometry (ICP-AES) using a Thermo Jarrel-Ash Iris Advantage HS instrument. Detection limits were $100 \mu \mathrm{g} \mathrm{L}-1$ for $\mathrm{K}$ and $\mathrm{Na}$, and $50 \mu \mathrm{g} \mathrm{L}-1$ for the rest. The analytical error was estimated below $3 \%$. In the ICP-AES analyses, calibration with three laboratory sets of standards was performed every 10 samples, and regression coefficients of the calibration curves exceeded 0.999.

$\mathrm{pH}$ and temperature (Thermo Scientific 9157BN Triode $\mathrm{pH}$ electrode, refillable), electrical conductivity (Hanna Instruments, $76302 \mathrm{~W}$ conductivity probe) and dissolved oxygen (Hanna Instruments, HI 76407/4 DO probe) were measured during the assembling/disassembling procedure with specific electrodes. Alkalinity was measured with a drop test kit Taylor K-1726, with a precision of $0.5 \mathrm{mmol} \mathrm{L}^{-1}$.

Samples for analysis of atenolol were filtered at $0.45 \mu \mathrm{m}$ using WATERS Syringe filter with PTFE membrane. Then, they were kept frozen until analysis, which was performed by using on-line solid phase extraction-liquid chromatographytandem mass spectrometry. Briefly, water samples $(10 \mathrm{~mL})$ spiked with the isotopically labeled compound at a concentration of $200 \mathrm{ng} \mathrm{L}^{-1}$, were extracted with the aid of an automated on-line SPE sample processor Prospekt- 2 from Spark Holland (Emmen, The Netherlands) connected in series with the LC-MS/MS instrument. Sample preconcentration was performed by passing $5 \mathrm{~mL}$ of the sample through a previously conditioned ( $1 \mathrm{~mL}$ MeOH plus $1 \mathrm{~mL}$ HPLC water) Oasis HLB Prospekt ${ }^{\mathrm{TM}}$ cartridge $(10 \times 1 \mathrm{~mm})$ from Waters (Mildford, MA, USA). After sample loading, the cartridge was washed with $1 \mathrm{~mL}$ of a $5 \%$ methanol water solution and further eluted with the chromatographic mobile phase. Chromatographic separation was performed with a Binary HPLC pump Model 1525 from Waters using a Purospher STAR RP-18e column $(125 \times 2 \mathrm{~mm}, 5 \mathrm{~m}$ particle diameter, from Merck, Darmstadt, Germany) and gradient elution with methanol and water as mobile phase. MS/MS detection was performed in the selected reaction monitoring (SRM) mode acquiring 2 SRM transitions per compound and 1 SRM transition per surrogate using a TOD triple-quadrupole mass spectrometer from Waters equipped with an electrospray interface. Quantitation was performed by the internal standard method using the corresponding deuterated compound as surrogate standard. Due to defective functioning (inaccurate sample volume acquisition) of the SPE processor, the first 3 results of the Mn(IV)-, $\mathrm{Fe}(\mathrm{III})$ - and $\mathrm{SO}_{4}$-reducing experiments and the first 2 results of the "natural conditions" experiment could only be considered as semiquantitative.

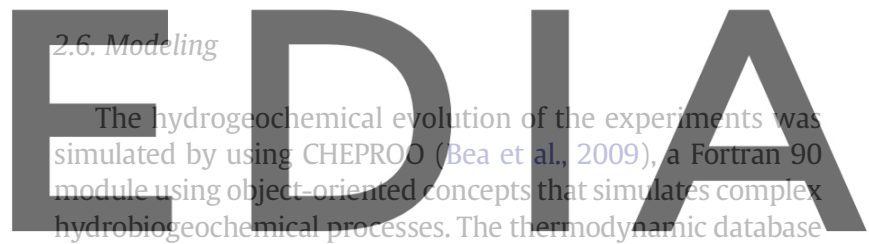

used was that of EQ3NR code (Wolery, 1992).

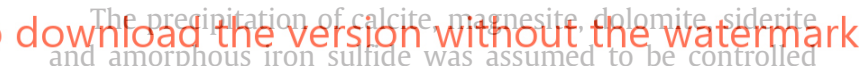

by kinetics. A simplified formulation was used to describe their reaction rate i $\left[\mathrm{mol} \mathrm{m}^{-3} \mathrm{~S}^{-1}\right]$ :

$r=k \sigma(1-\Omega)$

where $\mathrm{k}$ is a rate constant $\left[\mathrm{mol} \mathrm{m}^{-2} \mathrm{~s}^{-1}\right], \sigma$ is the reactive surface of the mineral $\left[\mathrm{m}^{2} \mathrm{~m}^{-3}\right]$, and $\Omega$ is the saturation ratio [-].

The microbially mediated redox reactions for the organic substrates degradation (only the easily degradable substrates were considered, i.e. acetate and methanol) were described by kinetic rate laws based on Monod expressions:

$r_{i}=k_{i} S \cdot \frac{T E A}{K_{i_{-} T E A}+T E A} \cdot \frac{K_{\text {inhib_I }}}{K_{\text {inhib_I }}+I}\left(\Omega_{i}-1\right)^{\eta_{i}}$

where $r_{i}$ is the rate of consumption of the substrate [ $\left.\mathrm{mol} \mathrm{L}^{-1} \mathrm{~s}^{-1}\right], \mathrm{k}_{\mathrm{i}}$ is the first order rate coefficient $\left[\mathrm{s}^{-1}\right], \mathrm{S}$ is the substrate concentration [ $\mathrm{mol} \mathrm{L}^{-1}$ ], TEA is the concentration of the particular Terminal Electron Acceptor [ $\mathrm{mol} \mathrm{L}^{-1}$ ], $\mathrm{K}_{\mathrm{i} \_ \text {TEA }}$ is the Monod half saturation constant with respect to TEA [ $\mathrm{mol} \mathrm{L}^{-1}$ ], $I$ is the concentration of an inhibiting substance (e.g. a competing TEA) $\left[\mathrm{mol} \mathrm{L}^{-1}\right]$ and $\mathrm{K}_{\text {inhib_I }}$ is the inhibition constant $\left[\mathrm{mol} \mathrm{L}^{-1}\right]$. The last term of expression (2), also called far-from-equilibrium term and where $\Omega_{\mathrm{i}}$ is the saturation ratio (ratio between ion activity product and equilibrium constant 
of the redox reaction "i") and $\eta_{\mathrm{i}}$ is an experimental parameter, describes the thermodynamic constraint for the redox reaction "i". In our case, $\Omega_{\mathrm{i}}$ is $\ll 1$ because of the high concentrations of organic substrates and the precipitation as mineral of large amounts of reaction products. Thus, the effect of such term on the absolute value of $r_{i}$ is insignificant. Multiple Monod and inhibition terms could be included in Eq. (2) if deemed necessary.

\section{Results and discussion}

\subsection{General water chemistry}

According to the reactions of Table 1 , a general trend of decrease in DOC and increase in alkalinity was expected in the biotic experiments. A simultaneous decrease in the concentration of the target dissolved electron acceptors was expected for the $\mathrm{NO}_{3}$ - and $\mathrm{SO}_{4}$-reducing experiments, whereas an increase in the concentration of Fe(II) and Mn(II), products of the reduction of the target solid electron acceptors, was expected in the Mn- and Fe-reducing experiments. Details on the geochemical evolution (experimental datasets and simulations) of the biotic experiments are given below. The results from duplicate batches showed a satisfactory reproducibility at all sampling times. Actually, when plotting

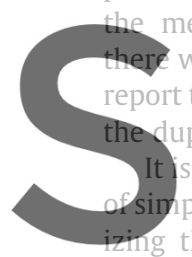
was always some overlap. eport the average of results and neduplicate bottles.

\section{worth mentioning that} plicity and according to the n
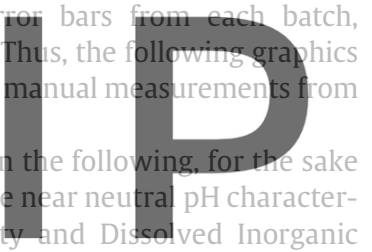
Carbon (DIC) have been considered practically equal to the

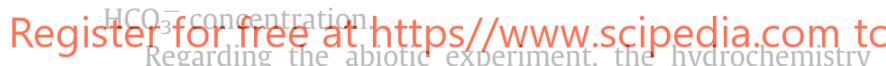
remained practically constant for the whole time as expected (results not shown).
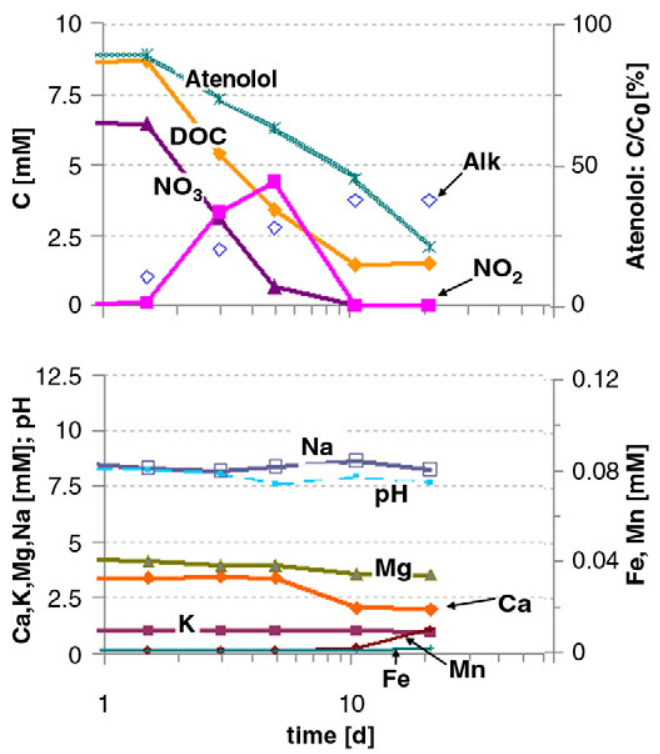

Fig. 1. Chemical evolution with time in the $\mathrm{NO}_{3}$-reducing experiment.

\subsection{1. $\mathrm{NO}_{3}$-reducing experiment}

Results from the $\mathrm{NO}_{3}$-reducing experiment are shown in Fig. 1. During the first 10 days, DOC decreased from $9.7 \mathrm{mmol} \mathrm{L}^{-1}$ to $1.5 \mathrm{mmol} \mathrm{L}^{-1}$. Afterwards it remained practically constant. At day 10 , the $6.7 \mathrm{mmol} \mathrm{L}^{-1}$ of nitrate initially present in the water have disappeared. Nitrite concentration began to increase after only some $12 \mathrm{~h}$, reaching a maximum at day 5 and becoming completely depleted by day 10 . Very low concentrations of dissolved manganese and iron were detected after day 10, presumably from the dissolution and reduction of small quantities of the Mn and Fe oxides naturally present in the sediment. Sulfate remained constant during the whole experiment.

These observations suggest that nitrate reducing conditions were established within a short period ( $\sim 0.5$ days) of microbial adaptation and dominated the system during the first 10 days. The increase of nitrite, followed by its depletion, reflected the actual pathway for nitrate reduction, with nitrite being an intermediate product between nitrate and nitrogen. After day 10, a different more reducing condition was established.

The experiment was planned to guarantee complete depletion of organic carbon with excess of nitrate, allowing nitratereducing conditions to dominate during longer time. However, the actual initial nitrate and DOC concentrations (6.7 and $9.7 \mathrm{mmol} \mathrm{L}^{-1}$, respectively) turned out to be different

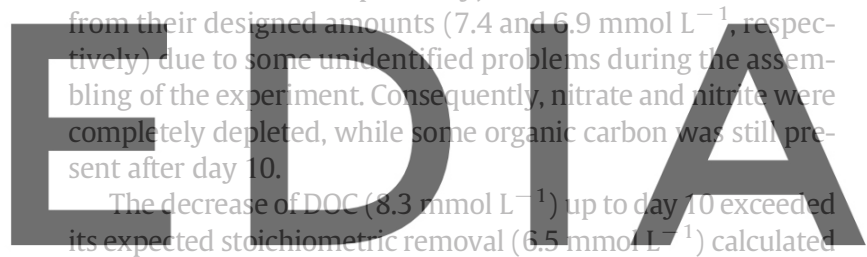

by assuming that the only process that can change nitrate con-

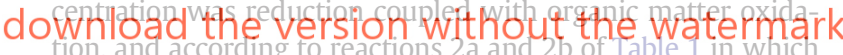

biomass formation is not taken into account. This suggests that some organic carbon was used into microorganisms' growth. An estimation of such investment could be made by introducing an additional reaction. In fact, since carbon in bulk biomass has a redox state of 0 , the formation of biomass requires a partial oxidation in the case of methanol (redox state of carbon $=-2$ ). Coupling it with the reduction of nitrate, the following stoichiometry could be written:

$\mathrm{CH}_{3} \mathrm{OH}+0.4 \mathrm{NO}_{3}{ }^{-}+0.4 \mathrm{H}^{+} \rightarrow \mathrm{CH}_{2} \mathrm{O}+0.2 \mathrm{~N}_{2}+1.2 \mathrm{H}_{2} \mathrm{O} \quad$ (reaction2c)

where $\mathrm{CH}_{2} \mathrm{O}$ has been used as simplified formula for biomass.

By using reactions $2 \mathrm{a}$ and $2 \mathrm{~b}$ of Table 1 , and reaction $2 \mathrm{c}$, a conversion of $2.2 \mathrm{mmol} \mathrm{L}^{-1}$ of organic carbon into biomass could be finally calculated, i.e. about $27 \%$ of the total organic carbon consumption.

Alkalinity increased with time, but its final value at day 10 (3.75 $\mathrm{mmol} \mathrm{L}^{-1}$ ) was smaller than the expected one ( $7 \mathrm{mmol} \mathrm{L}^{-1}$ ) calculated by taking into account the amount of organic substrate mineralized under the previous hypothesis. Part of this gap could be explained by the net reduction of $\mathrm{Ca}$ and $\mathrm{Mg}$ concentrations $\left(0.9 \mathrm{mmol} \mathrm{L}^{-1}\right.$ and $1.1 \mathrm{mmol} \mathrm{L}^{-1}$, respectively), which suggests that precipitation of $\mathrm{CaCO}_{3}$, $\mathrm{MgCO}_{3}$ or mixed carbonates was limiting the actual increase 
in bicarbonate concentration. The Saturation Index (S.I.) of these minerals during the experiment supports this hypothesis. It ranged between 0.24 and 0.71 for calcite, and from 0.06 to 0.45 for magnesite. Throughout the paper, S.I. values were calculated using the PHREEQC code with WATEQ thermodynamic database (Parkhurst and Appelo, 1999). After the conclusion of the experiment, inspection of the sediment samples by SEM-EDS showed indeed small crystals of calcite and MgCa carbonates on the surface of the sediment grains (Fig. 2A).

We next consider the equilibrium of the aqueous carbonate species with the gas in the headspace of the bottles. By day 10 , about $0.3 \mathrm{mmol} \mathrm{L}^{-1}$ of inorganic carbon (representing the $7 \%$ of the total inorganic carbon inventory) have been transferred to the gas phase as $\mathrm{CO}_{2(\mathrm{~g})}$. Finally, taking into account the precision of alkalinity measurements $\left( \pm 0.5 \mathrm{mmol} \mathrm{L}^{-1}\right)$, the overall inorganic carbon mass balance could be closed with an error of about $15 \%$.

The simulations carried out with CHEPROO (Fig. 3) support the feasibility of the previous hypotheses. The most important parameters used are reported in Table S4 of the Supporting Information.

\subsection{2. $\mathrm{Mn}(\mathrm{III} / \mathrm{IV})$-reducing experiment}

Results from the manganese reducing experiment are shown in Fig. 4. DOC decreased with time from 6.7 to $1 \mathrm{mmol} \mathrm{L}^{-1}$, starting after day 7 and reaching a significant removal rate after day
14. The small initial $\mathrm{NO}_{3}\left(0.1 \mathrm{mmol} \mathrm{L}^{-1}\right)$ had already disappeared by day 7 (not shown), having only oxidized a small amount of DOC (a maximum of $0.2 \mathrm{mmol} \mathrm{L}^{-1}$ ). Consistently with DOC decrease, dissolved Mn increased from day 7 reaching a concentration of $0.1 \mathrm{mmol} \mathrm{L}^{-1}$ at day 25 , which is then maintained for the rest of the experiment. No Fe was detected and $\mathrm{SO}_{4}$ concentration remained almost constant during the whole experiment.

Alkalinity increased slightly until day 25 . Thereafter, up to day 42 it dropped down to a value that remained steady throughout the rest of the experiment. The net reduction of $\mathrm{Ca}$ and $\mathrm{Mg}$ concentrations $\left(1.3 \mathrm{mmol} \mathrm{L}^{-1}\right.$ and $1 \mathrm{mmol} \mathrm{L}^{-1}$, respectively) and a lower than expected increase of Mn concentration suggested precipitation of $\mathrm{Mg}-\mathrm{Ca}$ carbonates and $\mathrm{MnCO}_{3}$, limiting alkalinity and dissolved Mn. The computed S.I. with respect to calcite and rhodochrosite during the experiment (between -0.11 and 0.97 for calcite, and between 1.15 and 1.73 for rhodochrosite) supports this hypothesis. SEM-EDS examination of the sediments from the disassembled batches showed the presence of small crystals of calcite, Mn-bearing carbonates, Mg-Ca carbonates, and rhodochrosite (Fig. 2B)

Regarding the low Mn concentration detected, aside from the fact that a fraction of the original DOC was invested in biomass growth implying a smaller total $\mathrm{Mn}^{2+}$ production than that corresponding to the complete mineralization of all substrates, an additional explanation could be some $\mathrm{Mn}^{2+}$ adsorption on the
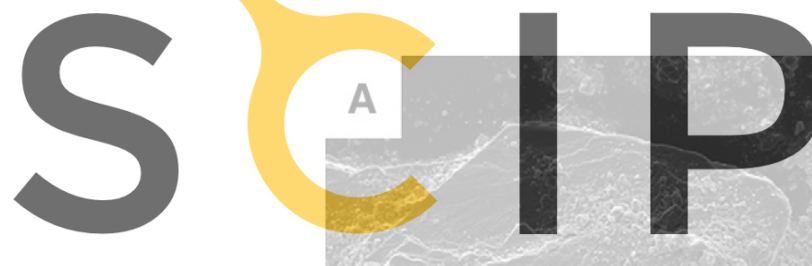

Register for free at https//www.scipedia.com to
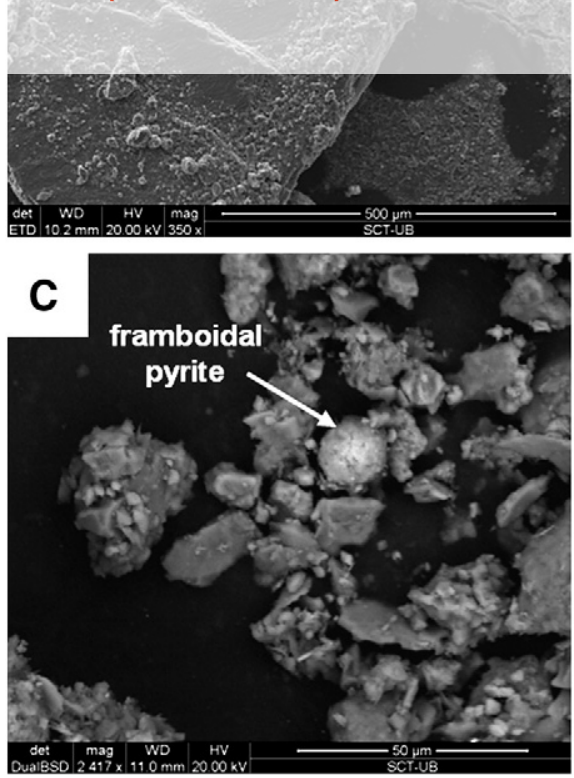
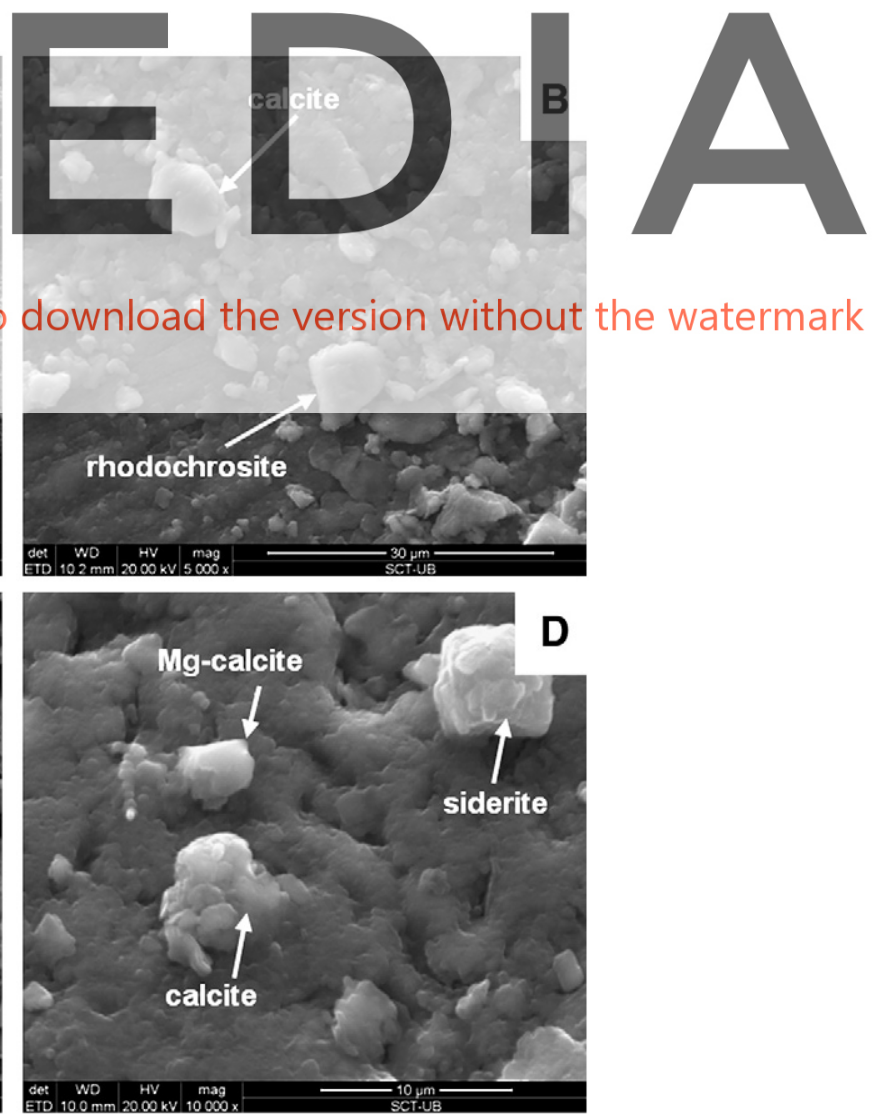

Fig. 2. SEM images of sediment samples from the disassembled batches. A) Neo-formed carbonate grains on the cleavage surface of a feldspar crystal present in the sediment in the $\mathrm{NO}_{3}$-reducing experiment. B) Precipitates of calcite and rhodochrosite in the Mn-reducing experiment. C) Precipitates of Ca-, Mg-Ca- and Fe-carbonates in the Fe-reducing experiment. D) Framboidal pyrite was occasionally observed in the Fe-reducing experiment, likely originated by the turnover of FeS previously precipitated. 

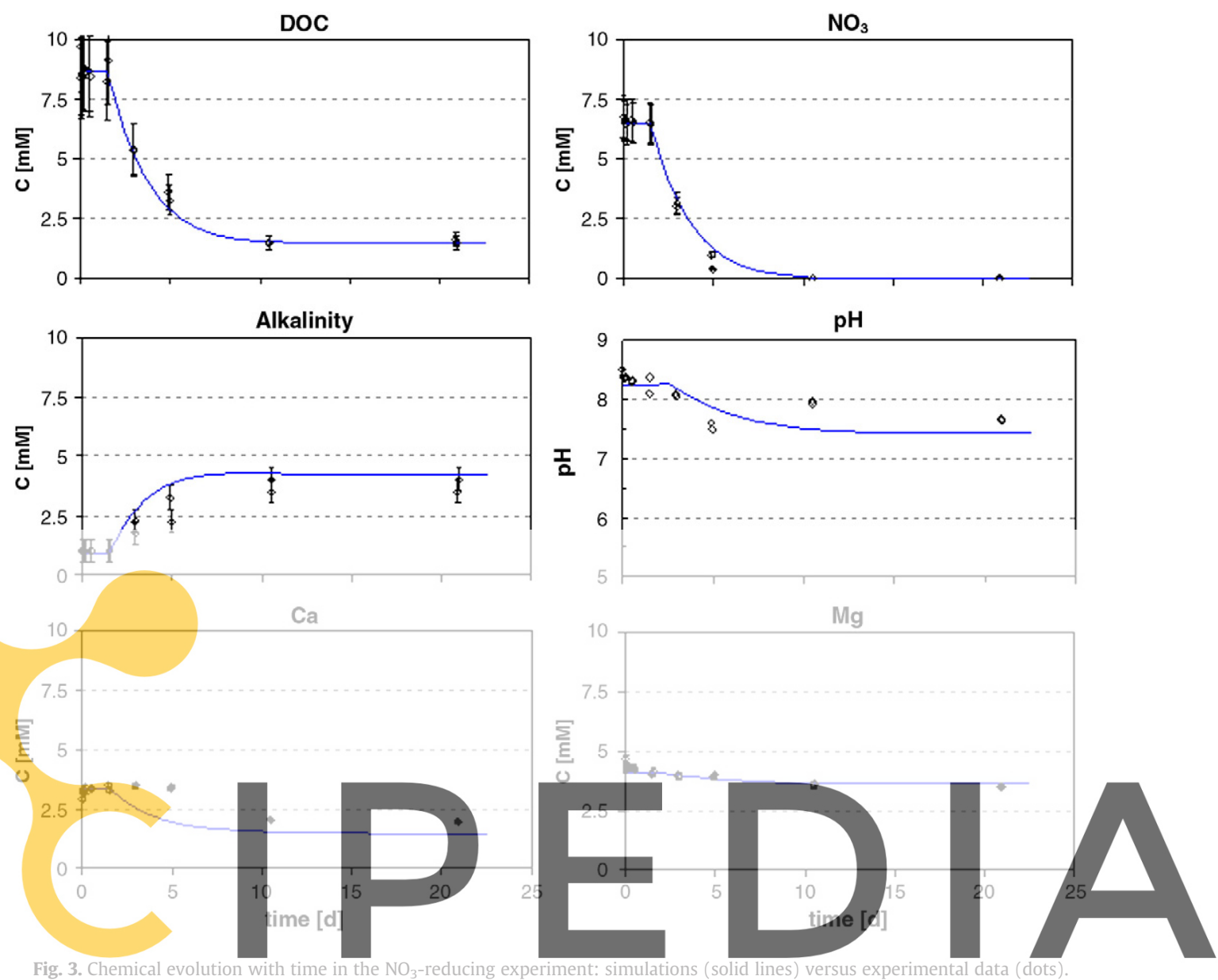

Fig. 3. Chemical evolution with time in the $\mathrm{NO}_{3}$-reducing experiment: simulations (solid lines) versus experimental data (dots).

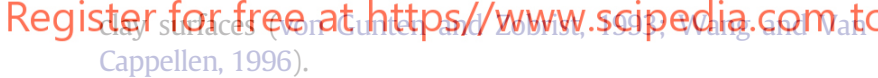

In summary, DOC and the redox sensitive species suggest that

Mn-reducing conditions were established after $\sim 1$ week of microbial adaptation and were then maintained during the test. The slow dissolution of the natural source of Mn(III/IV) used in the Mn reduction. Since the exact identity of the Mn oxide-hydroxides added could not be confirmed, an unequivocal mass balance for $\mathrm{C}$ and $\mathrm{Mn}$ (according to reactions 3.1a to 3.2b of Table 1) could not be carried out and quantitative modeling was not performed.
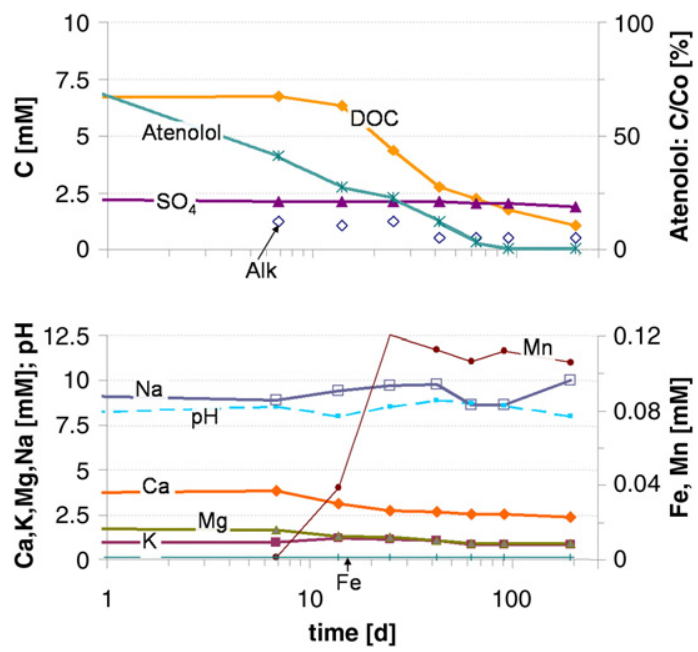

Fig. 4. Chemical evolution with time in the $\mathrm{Mn}(\mathrm{III} / \mathrm{IV})$-reducing experiment.

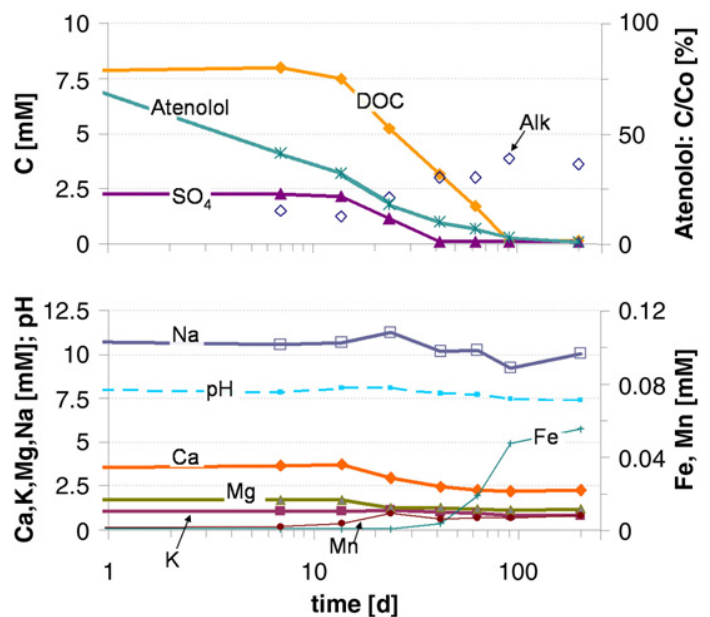

Fig. 5. Chemical evolution with time in the Fe(III)-reducing experiment. 


\subsubsection{Fe(III)-reducing experiment}

Results from the iron reducing experiment are shown in Fig. 5. A small decrease of DOC could be observed starting from day 7. By then, the small initial $\mathrm{NO}_{3}\left(0.1 \mathrm{mmol} \mathrm{L}^{-1}\right)$ had already disappeared (not shown), having oxidized a small amount of DOC (a maximum of $0.2 \mathrm{mmol} \mathrm{L}^{-1}$ ). Significant changes in water chemistry could be observed after day 14, but Fe was not detected until day 42, when the $2.3 \mathrm{mmol} \mathrm{L}^{-1}$ of initial $\mathrm{SO}_{4}$ had been completely depleted. After day 42 the dissolved $\mathrm{Fe}$ ( $\mathrm{Fe}$ (II) at the $\mathrm{pH}$ range of this experiment) increased slightly to about $0.06 \mathrm{mmol} \mathrm{L}^{-1}$. DOC decreased with time from 7.8 to $3.2 \mathrm{mmol} \mathrm{L}^{-1}$ at day 42 and to complete depletion after day 91 . Alkalinity increased from 1.2 to $3.0 \mathrm{mmol} \mathrm{L}^{-1}$ at day 42 and to $3.6 \mathrm{mmol} \mathrm{L}^{-1}$ thereafter. Ca and $\mathrm{Mg}$ concentrations decreased along the experiment: 1 and $0.6 \mathrm{mmol} \mathrm{L}^{-1}$ up to day 42 , and 0.2 and $0 \mathrm{mmol} \mathrm{L}^{-1}$ after day 42, respectively. A very low concentration of dissolved Mn, never exceeding $0.01 \mathrm{mmol} \mathrm{L}^{-1}$, was detected starting day 14. Probably it was produced by the reductive dissolution of some Mn mineral, naturally present in the sediments, causing a negligible effect on DOC concentration.

The above observations suggest that, after approximately 1 week of microbial adaptation, both $\mathrm{SO}_{4}$ and $\mathrm{Fe}$ (III) were reduced until day 42 causing FeS precipitation, whose low solubility prevented build up of dissolved Fe. This was confirmed by the dark color of the sediments at disassembling. Occasionally some framboidal pyrite has been observed by SEM-EDS on the surface of sediment grains (Fig. 2C), likely generated by the aging of precipitated FeS. Since dissolved Fe did not increase until $\mathrm{SO}_{4}$ was exhausted, the rate of $\mathrm{Fe}$ (III)reduction needs to be slower than $\mathrm{SO}_{4}$-reduction. While this would contradict the sequence of Table 1, it was not entirely surprising since the Fe(III) source was a natural solid phase. Slow dissolution of this source may be the rate limiting mechanism for Fe reduction. This means that $\mathrm{HS}^{-}$could be in part accumulated in solution. Concomitant Fe(III)- and $\mathrm{SO}_{4}$-reduction and iron sulfide precipitation has already been observed in field and laboratory studies (Brown et al., 2000 and references therein; Jakobsen and Postma, 1999; Ludvigsen et al., 1998; Weiner et al., 1998). After day 42, $\mathrm{SO}_{4}$ was exhausted and $\mathrm{Fe}(\mathrm{III})$ reducing conditions were likely to be dominating the system. In fact, concomitant occurrence of methanogenesis could not be excluded after day 42 , favored by the slow rate of Fe(III)-reduction. Coupling the two processes with siderite precipitation, this could represent another limiting factor for the increase of Fe(II) concentration. Similar scenarios have been already reported in literature (Jakobsen and Cold, 2007). Additional potential explanations for the low Fe(II) concentration detected, aside from the fact that the investment of some DOC in biomass
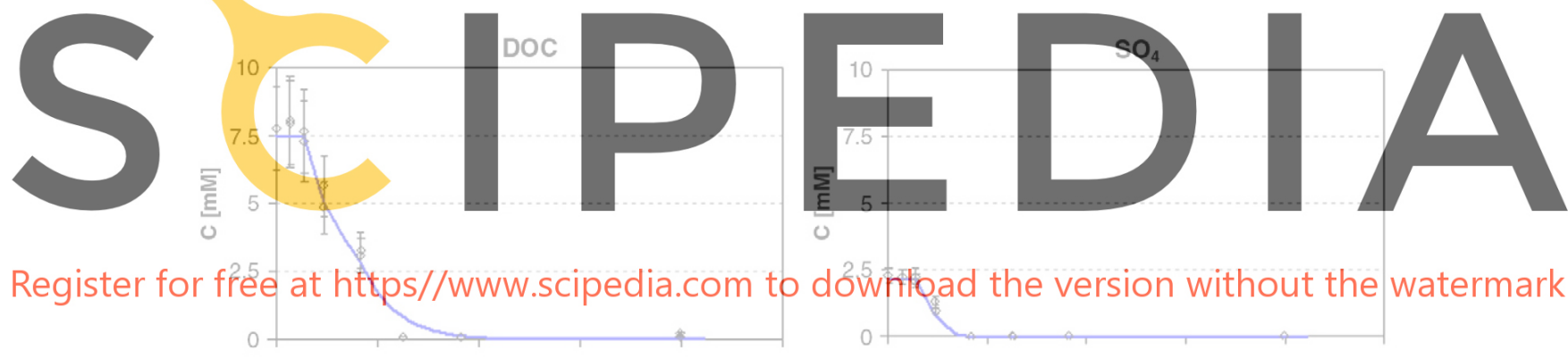

Register for frée at https//www.scipedia.com to ○
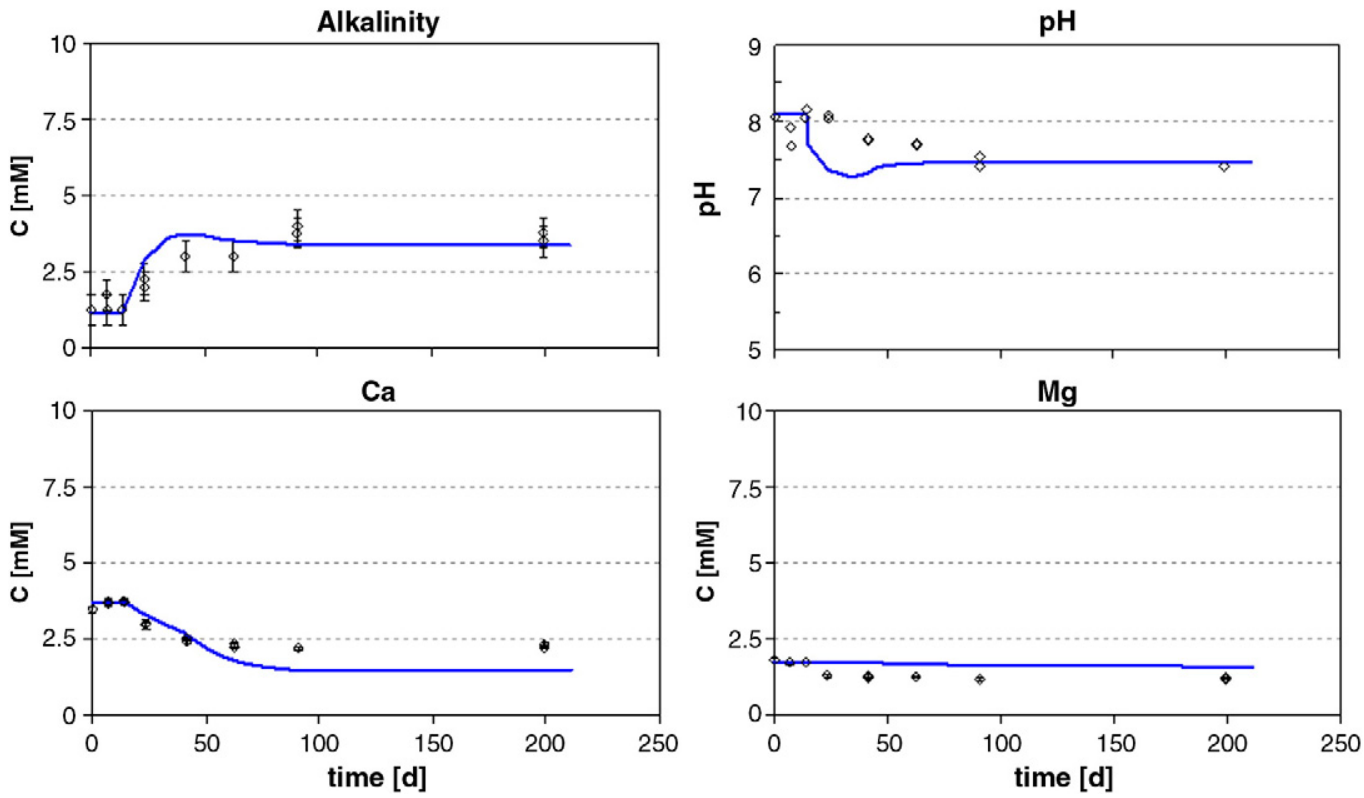

Fig. 6. Chemical evolution with time in the Fe(III)-reducing experiment: simulation " $A$ " (solid lines) versus experimental data (dots). 
growth implies a smaller Fe(II) production than mineralization, could be some $\mathrm{Fe}(\mathrm{II})$ adsorption onto clay surfaces (Wang and Van Cappellen, 1996) and/or its incorporation with some remaining solid $\mathrm{Fe}(\mathrm{III})$ to form magnetite (mixed $\mathrm{Fe}(\mathrm{II})-\mathrm{Fe}(\mathrm{III})$ oxide) (Broholm and Arvin, 2000 and references therein; Brown et al., 2000; Lovley and Phillips, 1988).

Small crystals of calcite, $\mathrm{Mg}-\mathrm{Ca}$ carbonates and siderite were observed on the surface of sediment grains (Fig. 2D), confirming that indeed precipitation of carbonates was limiting the increase of alkalinity.

When modeling the experiment with CHEPROO, the best fits of experimental data were obtained under the hypothesis of organic matter being degraded during the first part of the experiment by $\mathrm{SO}_{4}$ and, to a lesser extent, by $\mathrm{Fe}(\mathrm{III})$; then, after $\mathrm{SO}_{4}$ depletion, concomitant Fe-reduction and methanogenesis were assumed to be responsible of the organic substrate consumption (Fig. 6). The most important parameters used in the simulation, identified as simulation " $\mathrm{A}$ " in the following, are detailed in Table S5 of the Supporting Information.

Among the numberless combinations of hypotheses likely accounting for the complex geochemical evolution of the experiment, the simulations presented in this section were carried out without taking into account biomass growth during $\mathrm{SO}_{4}$-reduction and methanogenesis.

The need of considering the occurrence of Fe(III)-reduction and methanogenesis beside $\mathrm{SO}_{4}$-reduction was suggested by the bigger departure between model results and measurements (Fig. 7) when considering the degradation of organic matter coupled with one of the following processes: $\mathrm{SO}_{4}$-reduction (in this case biomass growth was included) (simulation "B"); $\mathrm{SO}_{4}$-reduction and slow $\mathrm{Fe}(\mathrm{III})$-reduction (simulation "C"); $\mathrm{SO}_{4}$-reduction and fast $\mathrm{Fe}(\mathrm{III})$-reduction (simulation "D"); and $\mathrm{SO}_{4}$-reduction and methanogenesis (inhibited by $\mathrm{SO}_{4}$ presence) (simulation "E").

To be noted, moreover, that simulation "A" was obtained by considering inhibition of $\mathrm{Fe}(\mathrm{III})$-reduction in the presence of $\mathrm{SO}_{4}$. On the contrary, again, computed DOC and Alkalinity showed worst fits to experimental data (results not shown).

\subsection{4. $\mathrm{SO}_{4}$-reducing experiment}

Results from the sulfate reducing experiment are shown in Fig. 8. A small decrease of DOC occurred prior to day 7, part of it (a maximum of $0.2 \mathrm{mmol} \mathrm{L}^{-1}$ ) being associated with the depletion of the initial $0.1 \mathrm{mmol} \mathrm{L}^{-1}$ of $\mathrm{NO}_{3}$ (not shown). Nevertheless, the significant decreases in both DOC and $\mathrm{SO}_{4}$ could be observed between days 18 and 65 . By then, the initial $10.2 \mathrm{mmol} \mathrm{L}^{-1}$ of DOC have been almost depleted (about $0.3 \mathrm{mmol} \mathrm{L}^{-1}$ remaining) and $\mathrm{SO}_{4}$ concentration has decreased from the initial $5.3 \mathrm{mmol} \mathrm{L}^{-1}$ to $2.1 \mathrm{mmol} \mathrm{L}^{-1}$. After day $65, \mathrm{SO}_{4}$ continued decreasing down to $1.3 \mathrm{mmol} \mathrm{L}^{-1}$ at the end of the experiment despite the fact that DOC had been already practically exhausted. In parallel, alkalinity increased continuously from the initial $1.5 \mathrm{mmol} \mathrm{L}^{-1}$ to $4.3 \mathrm{mmol} \mathrm{L}^{-1}$ at day 65 , and up to $6.3 \mathrm{mmol} \mathrm{L}^{-1}$ by the end of the experiment. $\mathrm{Ca}$ and $\mathrm{Mg}$ concentrations decreased from 3.6 to $1.3 \mathrm{mmol} \mathrm{L}^{-1}$ and from 1.8 to $0.9 \mathrm{mmol} \mathrm{L}^{-1}$, respectively. A very low concentration of $\mathrm{Mn}$, never exceeding $0.01 \mathrm{mmol} \mathrm{L}^{-1}$, was detected during the whole experiment, probably associated to dissolution or reduction of some $\mathrm{Mn}$ mineral naturally present in the sediments, this having a negligible effect on DOC.
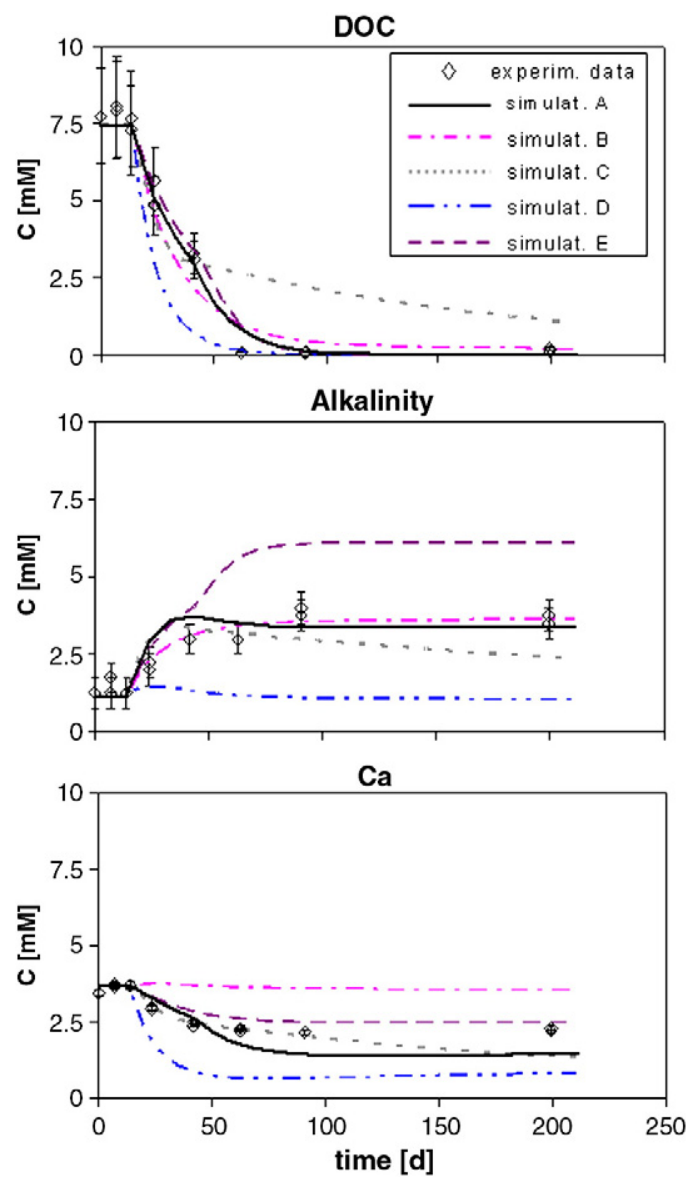

Fig. 7. Chemical evolution with time in the Fe(III)-reducing experiment: simulations (lines) versus experimental data (dots). Namely, regarding simulations: (A) $\mathrm{SO}_{4}$-reduction, $\mathrm{Fe}(\mathrm{III})$-reduction and methanogenesis (both the latter inhibited by $\mathrm{SO}_{4}$ ), (B) $\mathrm{SO}_{4}$-reduction (biomass growth included), (C) $\mathrm{SO}_{4}$-reduction and slow $\mathrm{Fe}$ (III)-reduction, (D) $\mathrm{SO}_{4}$-reduction and fast $\mathrm{Fe}(\mathrm{III})$-reduction, (E) $\mathrm{SO}_{4}$-reduction and methanogenesis (inhibited by $\mathrm{SO}_{4}$ ).
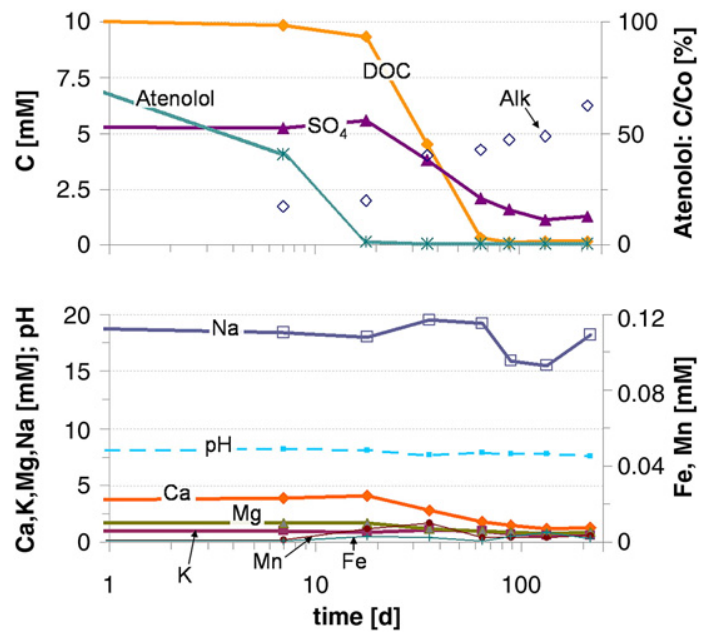

Fig. 8. Chemical evolution with time in the $\mathrm{SO}_{4}$-reducing experiment. 
As explained in the case of $\mathrm{Fe}(\mathrm{III})$ and as result of $\mathrm{SO}_{4^{-}}$ reduction, two alternative hypotheses might be formulated: (1) $\mathrm{HS}^{-}$remained in solution, or (2) $\mathrm{HS}^{-}$precipitated as FeS with the $\mathrm{Fe}^{2+}$ produced by reduction of some of the $\mathrm{Fe}$ (III) oxides present in the original sediment. Hypothesis (1) was supported by a decrease in charge balance error for the water samples up to day 65. Hypothesis (2) was supported by the dark color in the sediments after day 18.

Assuming hypothesis (1), by using the actual decrease in sulphate concentration $\left(3.2 \mathrm{mmol} \mathrm{L}^{-1}\right)$ and DOC $\left(9.9 \mathrm{mmol} \mathrm{L}^{-1}\right)$, the stoichiometries in Table 1 and the additional reactions:

$\mathrm{CH}_{3} \mathrm{OH}+2 \mathrm{Fe}(\mathrm{OH})_{3}(\mathrm{~s})+4 \mathrm{H}^{+} \rightarrow \mathrm{CH}_{2} \mathrm{O}+2 \mathrm{Fe}^{2+}+6 \mathrm{H}_{2} \mathrm{O} \quad$ (reaction4c)

$\mathrm{CH}_{3} \mathrm{OH}+0.25 \mathrm{SO}_{4}{ }^{2-}+0.25 \mathrm{H}^{+} \rightarrow \mathrm{CH}_{2} \mathrm{O}+0.25 \mathrm{HS}^{-}+\mathrm{H}_{2} \mathrm{O} \quad$ (reaction5c)

to take into account that in the case of methanol the formation of biomass (simplified formula: $\mathrm{CH}_{2} \mathrm{O}$ ) requires a partial oxidation too, it could be calculated that a total amount of $5.3 \mathrm{mmol} \mathrm{L}^{-1}$ DOC was mineralized up to day 65 while $4.6 \mathrm{mmol} \mathrm{L}^{-1}$ were inverted into microorganisms' growth (47\%). Since sulfate still decreases and alkalinity increases after DOC is nearly exhausted, we concluded that biomass was reused (Alexander, 1999). Under this assumption and according with stoichiometry, to reduce the remaining $0.8 \mathrm{mmol} \mathrm{L}^{-1} \mathrm{SO}_{4}, 0.17 \mathrm{mmol} \mathrm{L}^{-1}$ of the remaining DOC and some $1.5 \mathrm{mmol} \mathrm{L}^{-1}$ of accumulated biomass were further mineralized after day 65 . Thus, the "net" investment of DOC into biomass during the whole experiment amounted to $3.1 \mathrm{mmol} \mathrm{L}^{-1}$. Global balance of the experiment implies that $69 \%$ of organic carbon decay was associated to mineralization of the organic substrates coupled with sulfate reduction, and 31\% was inverted into microorganisms' growth.

Assuming hypothesis (2), with some concomitant Fe(III) reduction occurring, a similar calculation could be made and the global balance resulted in 69 to $72 \%$ of organic carbon diminution associated to substrates mineralization coupled with sulfate reduction, a 7 to $10 \%$ coupled with $\mathrm{Fe}$ (III) reduction, and $21 \%$ of organic carbon inverted into microorganisms' growth.

Most likely, actual processes lied between these two extreme cases, implying that a fraction of the $\mathrm{HS}^{-}$remained in solution as aqueous species while part of it was precipitated as $\mathrm{FeS}$. In either case, $\mathrm{SO}_{4}$-reduction coupled with organic matter degradation was the dominating process during the experiment. A microbial equilibration period or the enmasking of $\mathrm{SO}_{4}$-reduction early stages by the analytical errors could explain the insignificant changes characterizing water chemistry during the first 7 to 18 days of the experiment.
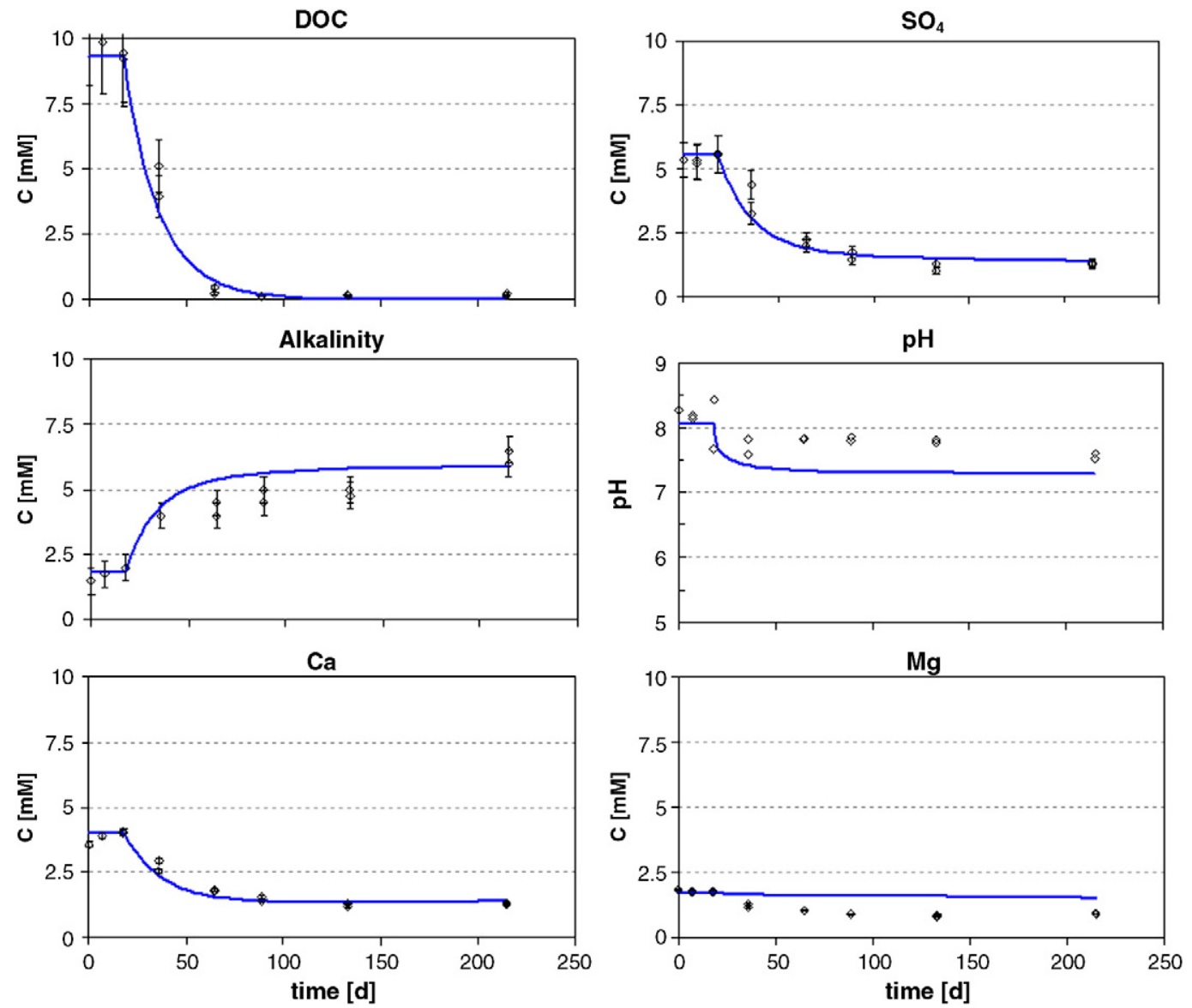

Fig. 9. Chemical evolution with time in the $\mathrm{SO}_{4}$-reducing experiment: simulations (solid lines) versus experimental data (dots). 
The total DOC mineralization estimated under both hypotheses (1) and (2) (6.9 and $7.9 \mathrm{mmol} \mathrm{L}^{-1}$, respectively) were higher than the measured increase in alkalinity $\left(4.8 \mathrm{mmol} \mathrm{L}^{-1}\right)$. Attributing the net reduction of $\mathrm{Ca}$ and $\mathrm{Mg}$ concentrations ( $2.3 \mathrm{mmol} \mathrm{L}^{-1}$ and $1 \mathrm{mmol} \mathrm{L}^{-1}$, respectively) to the precipitation of $\mathrm{Mg}$ and $\mathrm{Ca}$ carbonates, and taking into account the inorganic carbon present as gaseous phase in the headspace of the bottles as well as the precision of alkalinity measurements, the expected alkalinity fitted quite well the measured value. The resulting error in the global carbon balance amounts to about $13 \%$ and $1 \%$ under hypothesis (1) and (2), respectively. Indeed, $\mathrm{Mg}$ and Ca carbonate crystals were observed on the sediment grain surfaces.

The results for the simulations of the experiment chemical evolution under an intermediate case between hypothesis (1) and (2) are reported in Fig. 9. The most important parameters used are detailed in Table S6 of the Supporting Information.

\subsection{5. "natural conditions" experiment}

Results from the "natural conditions" experiment are shown in Fig. 10. The initial $2.5 \mathrm{mmol} \mathrm{L}^{-1}$ DOC were almost completely depleted, starting from the very beginning of the experiment. The initial $0.2 \mathrm{mmol} \mathrm{L}^{-1}$ of dissolved $\mathrm{O}_{2}$ (not shown) and $0.1 \mathrm{mmol} \mathrm{L}^{-1}$ of $\mathrm{NO}_{3}$ were totally removed after 1 and 3 days, respectively. Dissolved Mn was observed at approximately day 10 , reaching a maximum concentration of $0.03 \mathrm{mmol} \mathrm{L}^{-1}$ at day 62; then, Mn concentration decreased to about zero at the last sampling time of 192 days. Some dissolved Fe was detected between days 15 and 62, never exceeding $0.02 \mathrm{mmol} \mathrm{L}^{-1}$. The initial $2.3 \mathrm{mmol} \mathrm{L}^{-1}$ $\mathrm{SO}_{4}$ decreased with some fluctuations to $1.9 \mathrm{mmol} \mathrm{L}^{-1}$, from day 15 to the end of the experiment. The alkalinity showed an overall increase during the experiment, from 0.5 to $2.3 \mathrm{mmol} \mathrm{L}^{-1}$.

To sum up, since no specific redox state was deliberately stimulated in the "natural conditions" experiment, the organic matter degradation reactions occurred in the expected se-
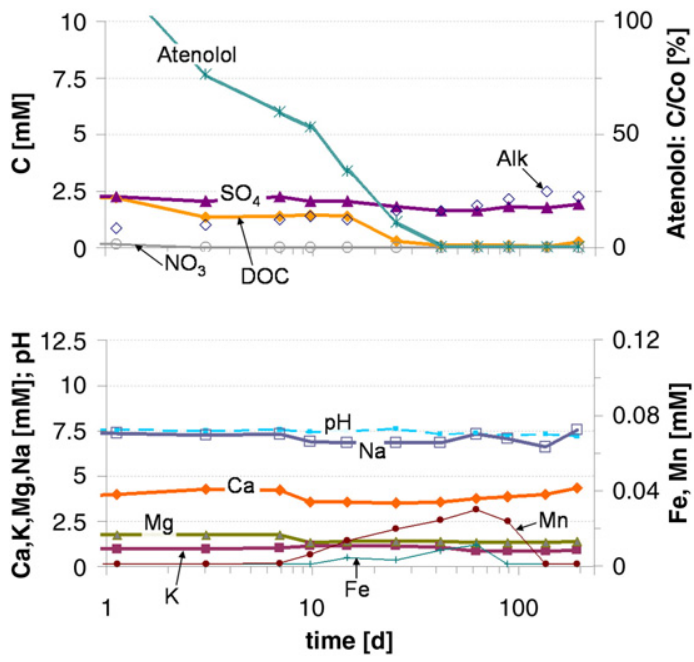

Fig. 10. Chemical evolution with time in the experiment performed under natural conditions. quence (Table 1, set "a” of reactions), until complete depletion of the specific electron acceptor (e.g. oxygen and nitrate) or, finally, of the electron donor. Aerobic degradation dominated the first day, and nitrate reduction appeared to control degradation until day 3. From there on, Fe and Mn-reducing conditions were found. These overlap with the $\mathrm{SO}_{4}$-reduction, which occurred after day 15. The presence of small zones of dark color in some of the retrieved solid suggested that some precipitation of iron sulfide occurred. Also the decrease in $\mathrm{Mg}\left(0.4 \mathrm{mmol} \mathrm{L}^{-1}\right)$, $\mathrm{Mn}\left(0.03 \mathrm{mmol} \mathrm{L}^{-1}\right)$ and $\mathrm{Fe}$ $\left(0.02 \mathrm{mmol} \mathrm{L}^{-1}\right)$ suggested that some carbonate precipitates. The overall $\mathrm{Ca}$ increase of about $0.8 \mathrm{mmol} \mathrm{L}^{-1}$ suggested carbonate dissolution, even if its concentration has been fluctuating during the experiment. Small crystals of $\mathrm{Mg}-\mathrm{Ca}$ carbonates and siderite have been observed on the surface of sediment grains.

\subsection{Fate of atenolol}

As example of application of the described microcosm study to the fate of emerging organic micropollutants under different redox conditions, the results for the $\beta$-blocker atenolol are presented. The temporal evolution of its average normalized concentration (with respect to each actual initial concentration $C_{0}$ ) for the 6 sets of experiments described above is shown in Fig. 11. The error bars were calculated by taking into account the analytical errors and the difference between duplicate batches results. Concentrations are presented in relative terms, normalized as $\mathrm{C} / \mathrm{Co}$, in order to remove systematic errors from the analysis.

The behavior of atenolol was similar in the $\mathrm{NO}_{3}$-reducing experiment than in the first 10 days of the "natural conditions" experiment. Little removal of atenolol was observed until day 1.5. Then concentrations started to decrease, following almost the same trend in both experiments and reaching an overall removal of about $50 \%$ at day 10 . In the $\mathrm{Mn}$ (III/IV)-, $\mathrm{Fe}(\mathrm{III})$ - and $\mathrm{SO}_{4}$-reducing tests, the lack of intermediate sampling points hindered the identification of atenolol behavior during the first week. Nevertheless, also in these three sets of experiments the same overall removal of atenolol of about $50 \%$ could be observed at day 7 .

After days 7-10, different evolutions of the concentration curves of atenolol could be identified for each set of batches.

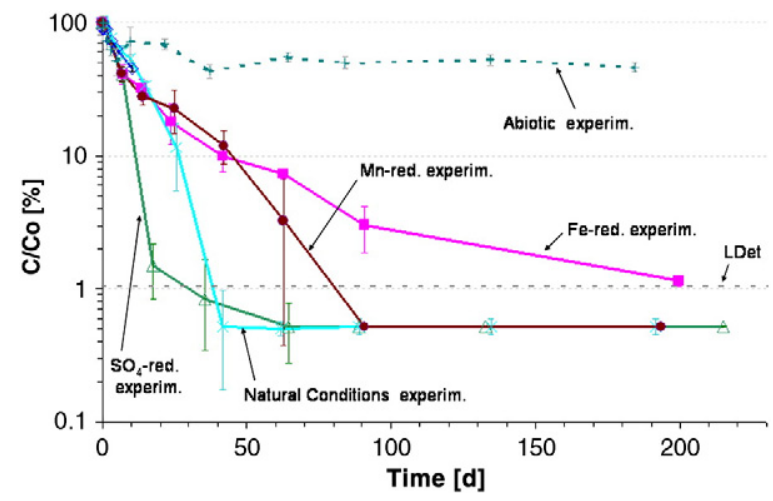

Fig. 11. Temporal evolution of the atenolol average normalized concentration in the different experiments. "LDet" stays for Limit of Determination. 
At day 18, complete removal of atenolol was reached in the $\mathrm{SO}_{4}$-reducing experiment. In fact, through the evolution of the general hydrochemistry we could not confirm if during this period the target redox condition was still being established or had already developed. Under Mn-reducing conditions, $90 \%$ of removal was reached at day 42, up to complete removal at day 91. Similarly, in the Fe(III)-reducing experiment, under actual mixed $\mathrm{Fe}-/ \mathrm{SO}_{4}$-reducing conditions, about $90 \%$ was removed at day 42 . Complete depletion occurred later on, almost at the end of the experiment, under the sole Fe-reducing or mixed Fe-reducing/methanogenetic conditions. In the "natural conditions" experiment, under some mixed $\mathrm{Mn}$ - $/ \mathrm{Fe}-/ \mathrm{SO}_{4}$-reducing conditions, complete removal of atenolol was reached already at day 42 .

Results for the abiotic experiment evidenced that, within the first 5 days, the removal trend for atenolol was the same observed in the $\mathrm{NO}_{3}$-reducing and "natural conditions" experiment, determining an overall removal of about $50 \%$. After day 5, taking into account the error bars, no additional removal could be observed.

Thus, the initial $\sim 50 \%$ removal of atenolol occurring within the first 5-10 days in all experiments could be attributed to some abiotic process, most likely sorption on the sediment grains. By then, some microbial processes were responsible of the remaining 50\% removal of atenolol. Different evolutions could be observed depending on the experiment, i.e. mainly depending on the redox conditions dominating or being established in each system. The $\mathrm{NO}_{3}$-reducing experiment was too short to be compared with the remaining tests. Yet, among the latter, qualitatively it could be assessed that the faster atenolol biotic removal was observed in the $\mathrm{SO}_{4}$-reducing experiment, under the most reducing (already established or still being established) condition up to that moment.

Aiming at a better characterization of atenolol biotic removal, a number of samples from the different experiments were analyzed looking for the potential presence of transformation products, specifically for atenololic acid. This compound was identified as product of atenolol microbial hydrolysis in a study of Radjenovic et al.(2008). The expectation to find atenololic acid at least in the $\mathrm{NO}_{3}$-reducing experiment was fostered by its occurrence in a similar experiment we carried out with much higher $\left(1 \mathrm{mg} \mathrm{L}^{-1}\right)$ initial atenolol concentration (Barbieri, 2011). Unfortunately, we found out that the analytical methodology used was not adequate to detect the potential presence of atenololic acid at concentrations in the $\mathrm{ng} \mathrm{L}^{-1}$ order of magnitude (in the experiment the maximum attainable concentration was $1 \mu \mathrm{g} \mathrm{L}^{-1}$ ). Thus, its presence could not be confirmed due to analytical restraints.

\section{Conclusions}

The following concluding considerations and remarks can be made on the present study:

- The desired redox states have been quite successfully created and sustained in each experiment. It is worth pointing that the use of natural sources of $\mathrm{Mn}$ and $\mathrm{Fe}$, as in the $\mathrm{Mn}$ - and Fe-reducing experiments, is realistic but complicates the development of controlled redox conditions. Natural sources are often quite crystalline, which slows down dissolution to the point of making it the rate limiting process.

- The assessment of the dominating redox states has been achieved by a thorough monitoring of water chemistry, focused on the redox-sensitive species but including major and minor ions too. Precipitation/dissolution of minerals as well as biomass production have to be taken into account for a correct interpretation of the main processes involved. Inspection of the sediments from the disassembled batch experiments through SEM-EDS has been fruitful to confirm the occurrence of such processes.

- However, further improvements are required. Specifically, dissolved sulfide and methane should be analyzed to better assess sulfate reducing conditions, especially in its early stages, and to check possible occurrence of methanogenesis. Additional desorption experiments could confirm $\mathrm{Mn}^{2+}$ and $\mathrm{Fe}^{2+}$ adsorption onto clay surfaces and/or exopolymeric substances (EPS). As general rule, whenever possible, the evaluation of the microbial state during the experiments (e.g.: identification of microbial communities, measurements of hydrogen, etc.) would be also advisable as complementary tool for the identification of the prevailing redox state.

- Numerical modeling proved useful in confirming the concepts described above with literature kinetic rates. Matches between computations and observations could have been improved by varying the rates of carbonates precipitation, and by postulating likely occurring sorption onto biofilms. Departures between model results and measurements are small, but generally suggest an intricate coupling between biologic and inorganic processes.

- The sampling schedules have proven adequate for monitoring the temporal evolution of aqueous chemistry and micropollutant concentrations. Still, in the case of $\mathrm{Mn}$-/Fe- $/ \mathrm{SO}_{4}$-reducing experiments some additional sampling point during the first week could have been useful to confirm atenolol early removal trends.

- One of the aims of the study was to test systems representative of real aquifers and of conditions occurring either naturally or possibly being stimulated during managed artificial recharge operations. Such conditions may vary spatially and temporally along with recharge cycles and recharge water composition. Thus, the microbial communities naturally existing in the sediments used in the experiments, which were expected to carry out the biodegradation of organic matter and the removal of micropollutants, were not previously adapted to the redox conditions of interest. As a consequence, the first part of each biotic experiment was characterized by a transition stage (of different duration) until the target redox state could be effectively established or observed. This hindered the interpretation of atenolol results. Anyway, after a common removal for all experiments, which we associate to abiotic processes, different microbial removal trends were observed for atenolol, depending on the different sets of batches, each one of them characterized by different redox conditions. The case of atenolol confirms that the redox state of the system could exert an influence on micropollutants behavior. Even if neither the $\mathrm{NO}_{3}$-reducing experiment was long enough to compare nitrate reducing conditions with the more reducing 
systems nor exact patterns could be isolated for each specific redox state, the faster atenolol biotic removal rate was observed in the $\mathrm{SO}_{4}$-reducing experiment, under the most reducing condition (while being established or in its early stage) up to that moment.

- Actually, correctly identifying of the actual biotic processes responsible for the removal of micropollutants (i.e. to distinguish biotransformation from biodegradation or even mineralization) requires the use of specific techniques, such as the use of isotopically labeled compounds and/or the identification of already known/new transformation products. In our study, for the case of atenolol we sought for its transformation product atenololic acid, but the presence of such compound could not be confirmed due to analytical restraints.

- Due to design constraints, the concentration of the easily degradable organic substrates used in the experiments were higher than those naturally present in aquifer systems or in most recharge waters, which likely affected the growth of the microbial communities present in the microcosms. Thus, regarding the micropollutant atenolol the extrapolation of its biotic removal rates to natural subsurface environments would have to be faced carefully, being not straightforward. Still, the microcosm study proved the feasibility of specific redox environments to develop at test site and the capability of the local microorganisms to eliminate the target micropollutant, providing as well some overall removal pattern under the tested settings. In the end, such scenarios could eventually be promoted during artificial recharge at test site if less favorable removals of atenolol are observed under the spontaneously occurring conditions.

- The removal of atenolol reported in the literature varies between 0 and $60 \%$ in conventional wastewater treatments, improving up to 77\% removal in advanced treatments such as Membrane Bioreactors (Gros et al., 2010; Radjenovic et al., 2009 and references therein). Thus, the overall complete removal observed in the experiments performed within this study suggests that the whole processes occurring in aquifers constitute a potentially efficient alternative water treatment for atenolol. Depending on the redox state naturally occurring or possibly being deliberately stimulated in field applications, the time needed for a complete removal may be ensured by the large residence times in aquifers. Actually, the results from the "natural conditions" experiment, which better resemble the potential conditions spontaneously occurring within the aquifer at Sant Vicenç test site during recharge, look very promising.

Supplementary materials related to this article can be found online at doi:10.1016/j.jconhyd.2011.09.003.

\section{Acknowledgments}

This work has been supported by the European projects GABARDINE, DECRAT (R + I Alliance), ENSAT (LIFE08 ENV/E/117), and by the Spanish Ministry of Science and Innovation (projects CGL2007-64551/HID and Consolider-Ingenio 2010 CSD200900065). The following persons are gratefully acknowledged: Albert Soler for the use of the glovebox, Anna Maria Solanas for the support on microbiological topics and Cristina Valhondo for the help in the assembling/disassembling of the last experiments. M.B. acknowledges AGAUR (Generalitat de Catalunya, Spain) for the economical support through a FI predoctoral grant. M.K. acknowledges the European Social Fund and AGAUR for their economical support through a FI pre-doctoral grant. Merck is acknowledged for the gift of LC columns. The final manuscript benefited from the comments of three anonymous reviewers.

\section{References}

Alexander, M., 1999. Biodegradation and Bioremediation, Second ed. Academic Press.

Aronson, D., Citra, M., Shuler, K., Printup, H., Howard, P., 1999. Aerobic biodegradation of organic chemicals in environmental media. A Summary of Field and Laboratory Studies. Final Report by Syracuse Research Corporation (New York).

Baker, M.A., Dahm, C.N., Valett, H.M., 1999. Acetate retention and metabolism in the hyporheic zone of a mountain stream. Limnology and Oceanography, American Society of Limnology and Oceanography 44 (6), 1530-1539.

Barber, L.B., Keefe, S.H., LeBlanc, D.R., Bradley, P.M., Chapelle, F.H., Meyer, M.T., Loftin, K.A., Kolpin, D.W., Rubio, F., 2009. Fate of sulfamethoxazole, 4-nonylphenol, and 17beta-estradiol in groundwater contaminated by wastewater treatment plant effluent. Environmental Science \& Technology, American Chemical Society 43 (13), 4843-4850.

Barbieri, M., 2011. Effect of redox conditions on the fate of emerging organic micropollutants during artificial recharge of groundwater: batch experiments. PhD thesis. Universitat Politecnica de Catalunya, UPCBarcelonaTech.

Baumgarten, B., Jährig, J., Reemtsma, T., Jekel, M., 2011. Long term laboratory column experiments to simulate bank filtration: factors controlling removal of sulfamethoxazole. Water Research 45 (1), 211-220.

Bea, S., Carrera, J., Ayora, C., Batlle, F., Saaltink, M., 2009. CHEPROO: a Fortran 90 object-oriented module to solve chemical processes in Earth Science models. Computers and Geosciences 35 (6), 1098-1112.

Bosma, T.N.P., Marlies, E., Ballemans, W., Hoekstra, N.K., Welscher, R.A.G., Smeenk, J.G., Schraa, G., Zehnder, A.J.B., 1996. Biotransformation of organics in soil columns and an infiltration area. Ground Water 34 (1), 49-56.

Bradley, P.M., Chapelle, F.H., Landmeyer, J.E., 2001. Effect of redox conditions on MTBE biodegradation in surface water sediments. Environmental Science and Technology 35 (23), 4643-4647.

Broholm, M.M., Arvin, E., 2000. Biodegradation of phenols in a sandstone aquifer under aerobic conditions and mixed nitrate and iron reducing conditions. Journal of Contaminant Hydrology 44 (3-4), 239-273.

Brown, C., Schoonen, M., Candela, J., 2000. Geochemical modeling of iron, sulfur, oxygen and carbon in a coastal plain aquifer. Journal of Hydrology 237 (3-4), 147-168.

Céspedes, R., Lacorte, S., Raldúa, D., Ginebreda, A., Barceló, D., Piña, B., 2005. Distribution of endocrine disruptors in the Llobregat River basin (Catalonia, NE Spain). Chemosphere 61, 1710-1719.

Christensen, T.H., Kjeldsen, P., Bjerg, P., Jensen, D., Christensen, J.B., Baun, A., Albrechtsen, H.J., Heron, G., 2001. Biogeochemistry of landfill leachate plumes. Applied Geochemistry 16 (7), 659-718.

Clara, M., Strenn, B., Kreuzinger, N., 2004. Carbamazepine as a possible anthropogenic marker in the aquatic environment: investigations on the behaviour of Carbamazepine in wastewater treatment and during groundwater infiltration. Water Research 38 (4), 947-954.

Crawford, J.J., Sims, G.K., Mulvaney, R.L., Radosevich, M., 1998. Biodegradation of atrazine under denitrifying condition. Applied Microbiology and Biotechnology 49 (5), 618-623.

Crawford, J.J., Traina, S.J., Tuovinen, O.H., 2000. Bacterial degradation of atrazine in redox potential gradients in fixed-film sand columns. Soil Science Society of America Journal 64 (2), 624-634.

Davis, J.W., Gonsior, S.J., Markham, D.A., Friederich, U., Hunziker, R.W., Ariano, J.M., 2006. Biodegradation and product identification of $\left[{ }^{14} \mathrm{C}\right]$ hexabromocyclododecane in wastewater sludge and freshwater aquatic sediment. Environmental Science \& Technology, American Chemical Society 40 (17), 5395-5401.

Díaz-Cruz, M.S., Barceló, D., 2008. Trace organic chemicals contamination in ground water recharge. Chemosphere 72 (3), 333-342.

Dold, B., 2003. Speciation of the most soluble phases in a sequential extraction procedure adapted for geochemical studies of copper sulfide mine waste. Journal of Geochemical Exploration 80, 55-68. 
Drewes, J., Heberer, T., Rauch, T., Reddersen, K., 2003. Fate of pharmaceuticals during ground water recharge. Ground Water Monitoring and Remediation 23 (3), 64-72.

Gröning, J., Held, C., Garten, C., Claußnitzer, U., Kaschabek, S.R., Schlömann, M., 2007. Transformation of diclofenac by the indigenous microflora of river sediments and identification of a major intermediate. Chemosphere 69 (4), 509-516.

Gros, M., Petrovic, M., Ginebreda, A., Barceló, D., 2010. Removal of pharmaceuticals during wastewater treatment and environmental risk assessment using hazard indexes. Environment International 36 (1), 15-26.

Heberer, T., 2007. Removal of pharmaceuticals during drinking water production. In: Petrovic, M., Barceló, D. (Eds.), Analysis, Fate and Removal of Pharmaceuticals in the Water Cycle, pp. 475-514 (Chapter 4.3).

Heberer, T., Massmann, G., Fanck, B., Taute, T., Dünnbier, U., 2008. Behaviour and redox sensitivity of antimicrobial residues during bank filtration. Chemosphere 73 (4), 451-460.

Hoppe-Jones, C., Oldham, G., Drewes, J.E., 2010. Attenuation of total organic carbon and unregulated trace organic chemicals in U.S. riverbank filtration systems. Water Research 44 (15), 4643-4659.

Hua, J., An, P., Winter, J., Gallert, C., 2003. Elimination of COD, microorganisms and pharmaceuticals from sewage by trickling through sandy soil below leaking sewers. Water Research 37 (18), 4395-4404.

Jakobsen, R., Cold, L., 2007. Geochemistry at the sulfate reduction-methanogenesis transition zone in an anoxic aquifer - a partial equilibrium interpretation using 2D reactive transport modeling. Geochimica et Cosmochimica Acta 71 (8), 1949-1966.

Jakobsen, R., Postma, D., 1999. Redox zoning, rates of sulfate reduction and interactions with Fe-reduction and methanogenesis in a shallow sandy aquifer, Rømø, Denmark. Geochimica et Cosmochimica Acta 63 (1), 137-151.

Kao, C.M., Chen, S.C., Wang, J.Y., Chen, Y.L., Lee, S.Z., 2003. Remediation of PCE-contaminated aquifer by an in situ two-layer biobarrier: laboratory batch and column studies. Water Research 37 (1), 27-38.

Katz, I., Dosoretz, C.G., Mandelbaum, R.T., Green, M., 2001. Atrazine degradation under denitrifying conditions in continuous culture of Pseudomonas ADP. Water Research 35 (13), 3272-3275.

Kerkhof, L.J., Williams, K.H., Long, P.E., McGuinness, L.R., 2011. Phase preference by active, acetate-utilizing bacteria at the rifle, CO integrated field research challenge site. Environmental Science and Technology 45 (4), 1250-1256.

Krueger, C.J., Radakovich, K.M., Sawyer, T.E., Barber, L.B., Smith, R.L., Field, J.A., 1998. Biodegradation of the surfactant linear alkylbenzenesulfonate in sewage-contaminated groundwater: a comparison of column experiments and field tracer tests. Environmental Science and Technology, American Chemical Society 32 (24), 3954-3961.

Löffler, D., Römbke, J., Meller, M., Ternes, T., 2005. Environmental fate of pharmaceuticals in water/sediment systems. Environmental Science and Technology 39, 5209-5218.

Lovley, D.R., Phillips, E.J.P., 1988. Novel mode of microbial energy metabolism: organic carbon oxidation coupled to dissimilatory reduction of iron or manganese. Applied and Environmental Microbiology 54 (6), $1472-1480$.

Lu, J., He, Y., Wu, J., Jin, Q., 2009. Aerobic and anaerobic biodegradation of nonylphenol ethoxylates in estuary sediment of Yangtze River, China. Environmental Geology 57 (1), 1-8.

Ludvigsen, L., Albrechtsen, H.J., Heron, G., Bjerg, P., Christensen, T.H., 1998. Anaerobic microbial redox processes in a landfill leachate contaminated aquifer (Grindsted, Denmark). Journal of Contaminant Hydrology 33, 273-291.

Mansell, J., Drewes, J., 2004. Fate of steroidal hormones during soil-aquifer treatment. Ground Water Monitoring and Remediation 24 (2).

Massmann, G., Dünnbier, U., Heberer, T., Taute, T., 2008. Behaviour and redox sensitivity of pharmaceutical residues during bank filtration - investigation of residues of phenazone-type analgesics. Chemosphere 71 (8), 1476-1485.

Montgomery-Brown, J., Drewes, J.E., Fox, P., Reinhard, M., 2003. Behavior of alkylphenol polyethoxylate metabolites during soil aquifer treatment. Water Research 37 (15), 3672-3681.

Muñoz, I., López-Doval, J.C., Ricart, M., Villagrasa, M., Brix, R., Geiszinger, A., Ginebreda, A., Guasch, H., de Alda, M.J.L., Romaní, A.M., Sabater, S., Barceló, D., 2009. Bridging levels of pharmaceuticals in river water with biological community structure in the Llobregat river basin (Northeast Spain). Environmental Toxicology and Chemistry 28 (12), 2706-2714.

Neuhauser, E.F., Ripp, J.A., Azzolina, N.A., Madsen, E.L., Mauro, D.M., Taylor, T., 2009. Monitored natural attenuation of manufactured gas plant tar mono- and polycyclic aromatic hydrocarbons in ground water: a 14-year field study. Ground Water Monitoring and Remediation 29 (3), 66-76.

Onesios, K., Yu, J., Bouwer, E., 2009. Biodegradation and removal of pharmaceuticals and personal care products in treatment systems: a review. Biodegradation 20 (4), 441-466 (Springer Netherlands).
Parkhurst, D.L., Appelo, C.A.J., 1999. User's guide to PHREEOC (version 2)-a computer program for speciation, batch-reaction, one-dimensional transport, and inverse geochemical calculations. U.S. Geological Survey, Water Resources Investigations Report 99-4259.

Pavelic, P., Nicholson, B.C., Dillon, P.J., Barry, K.E., 2005. Fate of disinfection by-products in groundwater during aquifer storage and recovery with reclaimed water. Journal of Contaminant Hydrology 77, 351-373.

Petrovic, M., Lopez de Alda, M., Diaz-Cruz, S., Postigo, C.J.R., Gros, M., Barcelo, D., 2009. Fate and removal of pharmaceuticals and illicit drugs in conventional and membrane bioreactor wastewater treatment plants and by riverbank filtration. Philosophical Transactions of the Royal Society A 367, 3979-4003.

Quintana, J.B., Weiss, S., Reemtsma, T., 2005. Pathways and metabolites of microbial degradation of selected acidic pharmaceutical and their occurrence in municipal wastewater treated by a membrane bioreactor. Water Research 39 (12), 2654-2664.

Radjenovic, J., Pérez, S., Petrovic, M., Barceló, D., 2008. Identification and structural characterization of biodegradation products of atenolol and glibenclamide by liquid chromatography coupled to hybrid quadrupole time-of-flight and quadrupole ion trap mass spectrometry. Journal of Chromatography. A 1210 (2), 142-153.

Radjenovic, J., Petrovic, M., Barceló, D., 2009. Fate and distribution of pharmaceuticals in wastewater and sewage sludge of the conventional activated sludge (CAS) and advanced membrane bioreactor (MBR) treatment. Water Research 43 (3), 831-841.

Radke, M., Lauwigi, C., Heinkele, G., Mürdter, T.E., Letzel, M., 2009. Fate of the antibiotic sulfamethoxazole and its two major human metabolites in a water sediment test. Environmental Science \& Technology, American Chemical Society 43 (9), 3135-3141.

Rauch-Williams, T., Hoppe-Jones, C., Drewes, J., 2010. The role of organic matter in the removal of emerging trace organic chemicals during managed aquifer recharge. Water Research 44, 449-460.

Rodriguez-Mozaz, S., López de Alda, M.J., Barceló, D., 2004. Monitoring of estrogens, pesticides and bisphenol $\mathrm{A}$ in natural waters and drinking water treatment plants by solid-phase extraction-liquid chromatographymass spectrometry. Journal of Chromatography. A 1045, 85-92.

Scheytt, T., Mersmann, P., Leidig, M., Pekdeger, A., Heberer, T., 2004. Transport of pharmaceutically active compounds in saturated laboratory columns. Ground Water 42 (5), 767-773.

Schulz, M., Löffler, D., Wagner, M., Ternes, T.A., 2008. Transformation of the $\mathrm{X}$-ray contrast medium iopromide in soil and biological wastewater treatment. Environmental Science and Technology 42 (19), 7207-7217.

Somsamak, P., Cowan, R.M., Häggblom, M.M., 2001. Anaerobic biotransformation of fuel oxygenates under sulfate-reducing conditions. FEMS Microbiology Ecology 37 (3), 259-264.

Stackelberg, P.E., Gibs, J., Furlong, E.T., Meyer, M.T., Zaugg, S.D., Lippincott, R.L., 2007. Efficiency of conventional drinking-water-treatment processes in removal of pharmaceuticals and other organic compounds. Science of the Total Environment 377 (2-3), 255-272.

Stasinakis, A.S., Kotsifa, S., Gatidou, G., Mamais, D., 2009. Diuron biodegradation in activated sludge batch reactors under aerobic and anoxic conditions. Water Research 43 (5), 1471-1479.

Stucki, G., Yu, C.W., Baumgartner, T., Gonzalez-Valero, J.F., 1995. Microbial atrazine mineralisation under carbon limited and denitrifying conditions. Water Research 29 (1), 291-296.

Tubau, I., Vázquez-Suñé, E., Carrera, J., González, S., Petrovic, M., López de Alda, M.J., Barceló, D., 2010. Occurrence and fate of alkylphenol polyethoxylate degradation products and linear alkylbenzene sulfonate surfactants in urban ground water: Barcelona case study. Journal of Hydrology 383, 102-110.

van der Zaan, B., de Weert, J., Rijnaarts, H., de Vos, W.M., Smidt, H., Gerritse, J., 2009. Degradation of 1,2-dichloroethane by microbial communities from river sediment at various redox conditions. Water Research 43 (13), 3207-3216

von Gunten, U., Zobrist, J., 1993. Biogeochemical changes in groundwaterinfiltration systems: column studies. Geochimica et Cosmochimica Acta 57 (16), 3895-3906.

Wang, Y., Van Cappellen, P., 1996. A multicomponent reactive transport model of early diagenesis: application to redox cycling in coastal marine sediments. Geochimica et Cosmochimica Acta 60 (16), 2993-3014.

Weiner, J.M., Lauck, T.S., Lovley, D.R., 1998. Enhanced anaerobic benzene degradation with the addition of sulfate. Bioremediation Journal 2 (3 and 4), 159-173.

Wolery, T.J., 1992. A computer program for geochemical aqueous speciationsolubility calculations: theoretical manual, user's guide and related documentation (version 7.0). URCL-MA-110662 PTIII. Lawrence Livermore Lab, Livermore, CA

Ying, G.-G., Toze, S., Hanna, J., Yu, X.-Y., Dillon, P.J., Kookana, R.S., 2008. Decay of endocrine-disrupting chemicals in aerobic and anoxic groundwater. Water Research 42 (4-5), 1133-1141.

Zwiener, C., Seeger, S., Glauner, T., Frimmel, F., 2002. Metabolites from the biodegradation of pharmaceutical residues of ibuprofen in biofilm reactors and batch experiments. Analytical and Bioanalytical Chemistry 372 (4), 569-575. 